NIST Technical Note 1785

\title{
Thermal Performance of Self- Contained Breathing Apparatus Facepiece Lenses Exposed to Radiant Heat Flux
}

Anthony Putorti Jr Amy Mensch*

Nelson Bryner

George Braga

\footnotetext{
* Current affiliation: Pennsylvania State University, University Park, PA.
} 
NIST Technical Note 1785

\section{Thermal Performance of Self-Contained Breathing Apparatus Facepiece Lenses Exposed to Radiant Heat Flux}

Anthony Putorti Jr

Amy Mensch

Nelson Bryner

Fire Research Division

Engineering Laboratory National Institute of Standards and Technology

Gaithersburg, MD 20899

George Braga Federal District Fire Department Brasília, Brazil

http://dx.doi.org/10.6028/NIST.TN.1785

February 2013

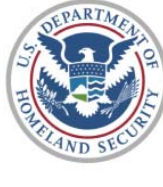

FEMA

U.S. Fire

Administration

Department of Homeland Security

Janet Napolitano, Secretary

Federal Emergency Management Agency

W. Craig Fugate, Administrator

United States Fire Administration

Ernest Mitchell, United States Fire Administrator

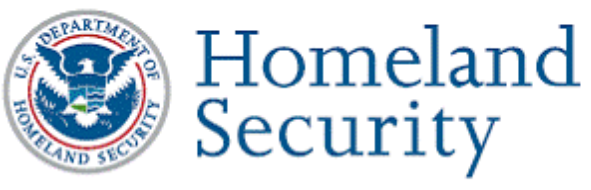

Science and Technology

Department of Homeland Security Janet Napolitano, Secretary

Science and Technology Tara O'Toole, Under Secretary

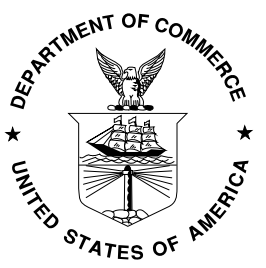

U.S. Department of Commerce Rebecca Blank, Acting Secretary

National Institute of Standards and Technology Patrick D. Gallagher, Under Secretary for Standards and Technology and Director 
Certain commercial entities, equipment, or materials may be identified in this document in order to describe an experimental procedure or concept adequately. Such identification is not intended to imply recommendation or endorsement by the National Institute of Standards and Technology, nor is it intended to imply that the entities, materials, or equipment are necessarily the best available for the purpose.

National Institute of Standards and Technology Technical Note 1785

Natl. Inst. Stand. Technol. Tech. Note 1785, 43 pages (February 2013)

http://dx.doi.org/10.6028/NIST.TN.1785

CODEN: NTNOEF 


\title{
Thermal Performance of Self-Contained Breathing Apparatus Facepiece Lenses When Exposed to Radiant Heat Flux
}

\begin{abstract}
Fire fighters are exposed to highly variable thermal environments including elevated temperatures, convective heat flux, and radiant heat flux, which can put a significant burden on personal protective equipment. Thermally degraded and melted self-contained breathing apparatus (SCBA) facepieces have been identified as a contributing factor in certain fire fighter fatalities and injuries in the United States. At the current time, standard performance tests for SCBA facepieces are conducted at less severe thermal conditions than other components of a fire fighter's ensemble and equipment.

In order to better understand the level of thermal performance of the SCBA facepiece lens and to develop an improved performance test method, facepieces were exposed to controlled and well characterized elevated thermal environments. In these experiments, SCBA facepieces were exposed to radiant heat fluxes of $2 \mathrm{~kW} / \mathrm{m}^{2}$ to $15 \mathrm{~kW} / \mathrm{m}^{2}$ from a natural gas fired radiant panel apparatus. The facepieces were mounted on a headform and instrumented with thermocouples to measure the temperatures of the exterior lens surface, the interior lens surface, inside the facepiece, on the headform, and in the airway of the headform during exposure. Heat flux to the headform was also measured during the exposures. Airflow through the mouth and respiratory system was simulated using a breathing apparatus, with the air to the mask supplied by an $\mathrm{SCBA}$, at an average flow rate of $40 \mathrm{~L} / \mathrm{min}$ at $24 \mathrm{breaths} / \mathrm{min}$. The pressure inside the facepiece was measured during the experiments.
\end{abstract}

During the experiments, the facepiece lenses sustained various degrees of thermal damage, ranging from no visible damage to the formation of crazing, bubbles, holes, and protuberant deformations. The maximum temperatures measured on the exterior of the lenses were approximately $290^{\circ} \mathrm{C}$, while the maximum airway temperatures were approximately $55^{\circ} \mathrm{C}$.

An incident radiant heat flux of $15 \mathrm{~kW} / \mathrm{m}^{2}$ was selected as representative of fire fighter exposure and as a useful test criterion for evaluating the performance of the SCBA facepiece lenses. Measurement of internal facepiece pressure was found to be a valuable method for determining the effect of holes on firefighter air supply duration and breathing protection. All of the SCBA facepieces tested exhibited holes in the lens in less than $5 \mathrm{~min}$ of exposure to $15 \mathrm{~kW} / \mathrm{m}^{2}$ of incident heat flux.

Although much was learned about conditions associated with thermal degradation of SCBA facepiece lenses, more research and development are needed to understand the thermal degradation of facepiece lenses and to develop equipment that better resists the radiant heat fluxes encountered by the fire service during structure fires. These experiments were conducted with support in part by the Department of Homeland Security Science and Technology Directorate and the United States Fire Administration.

Key words: SCBA, self-contained breathing apparatus, lens, performance metrics, radiant heat flux, respirator, radiant panel. 
TABLE OF CONTENTS

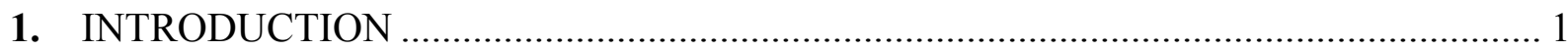

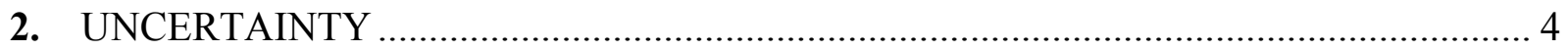

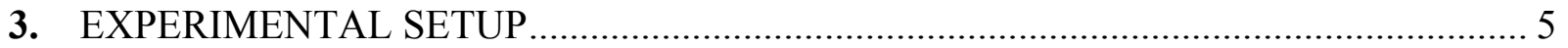

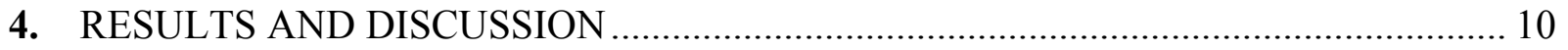

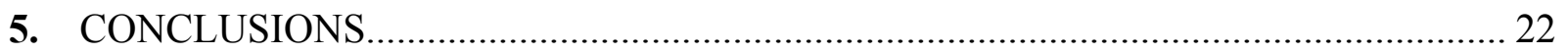

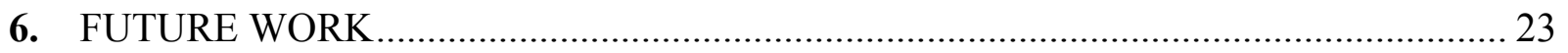

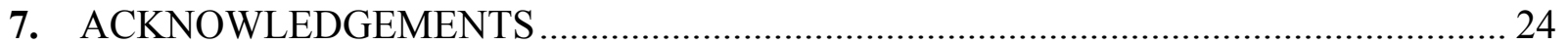

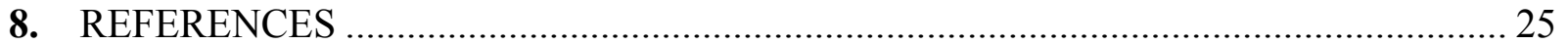

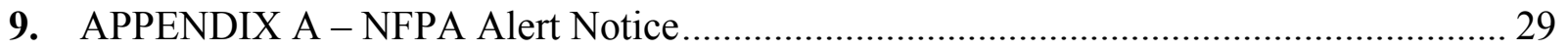

10. APPENDIX B - Apparatus Drawings and Images ........................................................ 31 


\section{INTRODUCTION}

Respiratory protection, in the form of a self-contained breathing apparatus (SCBA), is a critical component of a fire fighter's personal protective equipment because it protects the wearer from inhaling the life threatening atmosphere often present in and around the fire environment [1]. The SCBA lens forms a critical barrier that is designed to withstand physical and thermal impacts while maintaining integrity and visual acuity. Damage to the integrity of the lens can result in fire fighters being exposed to an environment that is immediately dangerous to life and health (IDLH), leaving the user susceptible to toxic materials and combustion products, asphyxiation, and thermal burns to the respiratory tract. Polycarbonate (PC) has been used for fire fighting SCBA lens applications due to its optical clarity, impact resistance, and thermal resistance. The SCBA lens typically has an abrasion-resistant coating to minimize scratching. The glass transition temperature of polycarbonate as reported in the literature is between $145^{\circ} \mathrm{C}$ $\left(293^{\circ} \mathrm{F}\right)$ and $150^{\circ} \mathrm{C}\left(302^{\circ} \mathrm{F}\right)$ [2]. Melting temperatures can vary widely depending on the type of polycarbonate, between $215^{\circ} \mathrm{C}\left(419^{\circ} \mathrm{F}\right)$ and $338^{\circ} \mathrm{C}\left(640^{\circ} \mathrm{F}\right)[2,3]$.

Structural fire fighting thermal environments are highly variable, and depend on many factors including fuel type and load (furniture, carpeting, etc.), interior finish, ventilation conditions, structure layout and construction, and the fire fighting tactics employed. Studies on fire fighter protective clothing [4-7] have described pre-flashover fire fighting environments with temperatures up to $300{ }^{\circ} \mathrm{C}\left(572^{\circ} \mathrm{F}\right)$ and maximum heat fluxes as high as $20 \mathrm{~kW} / \mathrm{m}^{2}$. More severe fire and fire fighting environments, where protective clothing has been studied, include temperatures up to $700{ }^{\circ} \mathrm{C}\left(1292{ }^{\circ} \mathrm{F}\right)$ and heat fluxes of $20 \mathrm{~kW} / \mathrm{m}^{2}$ to $40 \mathrm{~kW} / \mathrm{m}^{2}[4,5,8,9]$. Conditions of flashover and post-flashover, however, can reach $1000{ }^{\circ} \mathrm{C}\left(1832{ }^{\circ} \mathrm{F}\right)$ and $170 \mathrm{~kW} / \mathrm{m}^{2}[10,11]$. If SCBAs are to provide breathing protection during fire ground operations, they must provide positive pressure for an adequate period of time during pre-flashover conditions, and additional protection to allow for escape during rapidly changing transitions in the fire environment.

Currently, the US certification thermal performance requirements for fire fighter protective clothing and equipment are not consistent, with thermal performance requirements for SCBA being less than other equipment. Fire fighter structural fire fighting ensembles, for example, are tested using ISO 17492 Clothing for Protection Against Heat and Flame - Determination of Heat Transmission on Exposure to both Flame and Radiant Heat [12], as specified by NFPA 1971 Standard on Protective Ensembles for Structural Fire Fighting and Proximity Fire Fighting [13]. This test exposes fire fighting garments to a combined convective and radiant heat flux of $84 \mathrm{~kW} / \mathrm{m}^{2}$. Other pieces of firefighter equipment, such as Personal Alert Safety Systems (PASS) and Thermal Imaging Cameras (TIC) are subjected to a Heat Resistance Test $[14,15]$ in a convective circulating oven at $260^{\circ} \mathrm{C}\left(500^{\circ} \mathrm{F}\right)$ for $5 \mathrm{~min}$, and a Heat and Flame Test $[14,15]$ in an oven at $95{ }^{\circ} \mathrm{C}\left(203{ }^{\circ} \mathrm{F}\right)$ for $15 \mathrm{~min}$, followed by direct flame contact (at $815^{\circ} \mathrm{C}$ $\left[1500^{\circ} \mathrm{F}\right]$ to $\left.1150^{\circ} \mathrm{C}\left[2100^{\circ} \mathrm{F}\right]\right)$ for $10 \mathrm{~s}$.

The most severe thermal exposure for fire fighter SCBAs, however, is currently the Heat and Flame Test, Section 8.11, of NFPA 1981 Standard on Open Circuit Self-Contained Breathing Apparatus (SCBA) For Emergency Services [16]. In this test, the SCBA is mounted on a test headform attached to a breathing simulator operating at $40 \mathrm{~L} / \mathrm{min}$ and placed in a convection 
oven at $95^{\circ} \mathrm{C}\left(203{ }^{\circ} \mathrm{F}\right)$ for $15 \mathrm{~min}$. No more than $20 \mathrm{~s}$ later, the breathing rate is increased to $103 \mathrm{~L} / \mathrm{min}$, and the SCBA is exposed to direct flame contact (at $815^{\circ} \mathrm{C}\left[1500{ }^{\circ} \mathrm{F}\right]$ to $1150{ }^{\circ} \mathrm{C}$ $\left.\left[2100^{\circ} \mathrm{F}\right]\right)$ for $10 \mathrm{~s}$. Following the heat exposures, the headform is dropped from a height of 15.2 $\mathrm{cm}$ (6.0 in). The SCBA is tested for airflow performance and for visual acuity. Although the Heat and Flame Test involves elevated temperatures, the lack of a holistic thermal performance methodology in the standards development process results in thermal test conditions that are not as severe as those applied to the other fire fighting equipment. The Heat and Flame Test does not capture the conditions of temperature and heat flux that a fire fighter may experience during fire ground operations within a structure.

The need for improved SCBA and facepiece designs to withstand a variety of extreme conditions, including high heat loads, was documented in a U.S. Fire Administration special report in 2001 [17]. In the decade since, several reports on fire fighter fatalities have indicated that inadequate thermal performance of SCBA lenses was a contributing cause to one or more fire fighter fatalities [18-24]. In these incidents, the SCBA facepieces displayed extensive damage to the point that the SCBA could no longer provide protection from the hazardous environment. It was assumed that the facepieces failed before the fatalities occurred because the victims were found wearing the facepieces and thermal burns were found on their tracheae. In addition to these fatalities, there have been numerous anecdotal accounts of crazing, bubbling, and softening of lenses, some of which have been reported as near misses [25-28]. The fire environment in these specific incidents is not known, therefore, the specific types of thermal exposures or environmental conditions causing the failures have not been identified. In addition, there is a significant lack of information regarding the high temperature and high heat flux performance of SCBA. The need for further research in this area was listed in the Emergency First Responders Respirator Thermal Characteristics Workshop Proceedings [29] in order to develop more representative and realistic SCBA testing. The NFPA has also recently issued an Alert Notice [30] warning the fire service that fire fighting environments may cause thermal degradation of melting of facepiece lenses, resulting in the loss of respiratory system protection. A copy of the Alert Notice is included in Appendix A.

Previous investigators have studied thermal exposures of related fire fighting equipment and reported in the literature. Results from these studies give only a limited understanding of how current SCBA equipment performs. Quintiere [31], for example, examined radiative and convective heating of a polycarbonate face shield, which is typically fastened to a fire fighter's helmet. Held and Harder [32] investigated the thermal performance of SCBA models available in 1980, which were exposed to a variety of temperature extremes in an oven up to $250{ }^{\circ} \mathrm{C}$ $\left(482^{\circ} \mathrm{F}\right)$, a propane flame at $1050{ }^{\circ} \mathrm{C}\left(1922^{\circ} \mathrm{F}\right)$ for $10 \mathrm{~s}$, and a natural gas flame at $1000{ }^{\circ} \mathrm{C}$ $\left(1832{ }^{\circ} \mathrm{F}\right)$ to $1500{ }^{\circ} \mathrm{C}\left(2732^{\circ} \mathrm{F}\right)$ for $2 \mathrm{~s}$ and $4 \mathrm{~s}$. The resulting failures of many different components of the SCBA during the Held and Harder experiments led to the adoption of the Heat and Flame Test in the NFPA 1981 document, which included a burner array exposure for $15 \mathrm{~s}$ [16]. This standard test improved the design of the SCBA at that time and eliminated certain materials with a propensity for ignition or melting.

Recently, Mensch et al. [33] exposed current SCBA facepieces to fires in furnished townhouses to replicate thermal degradation from realistic fire environments and quantify the exposure conditions in terms of heat flux and temperature. Thermal degradation of SCBA facepiece 
lenses in the form of bubbling, loss of visual acuity, and severe deformation was observed for three facepieces, which were exposed to peak heat fluxes above $20 \mathrm{~kW} / \mathrm{m}^{2}$, but not necessarily high ambient air temperatures. In these cases, facepiece lens temperatures exceeded $200{ }^{\circ} \mathrm{C}$ $\left(392{ }^{\circ} \mathrm{F}\right)$, approaching the melting temperature of polycarbonate. The effect of a constant airflow of $40 \mathrm{~L} / \mathrm{min}$ through the facepiece was found to have a slight cooling effect, increasing the temperature difference between the interior and exterior surfaces of the facepiece by approximately $10{ }^{\circ} \mathrm{C}\left(20^{\circ} \mathrm{F}\right)$. Due to fire development driven variations, the exposure heat fluxes and temperatures varied substantially during the course of the experiments. Due to the harsh smoky environment within the townhouse, lenses could only be inspected after the exposure, and real time SCBA data collection was limited to lens temperature. Although the study was a valuable demonstration of the conditions capable of causing thermal degradation, more experiments were needed to better determine the thermal limits of SCBA facepieces.

The experiments in this report were performed to characterize the thermal performance of the SCBA facepiece lens as a function of radiant heat flux exposure in a controlled laboratory environment. A natural gas fired radiant panel provided constant and repeatable levels of incident heat flux on the facepiece lens. The facepiece performance was assessed through measurements of lens surface temperature, pressure within the facepiece, headform surface temperature, breathing air temperature, heat flux inside the facepiece, and inspection of video recordings.

The experimental data was analyzed to obtain the intensity and duration of exposure associated with cracking/crazing, bubbling, and deformation which compromise facepiece lens integrity. Examples of visibly discernible degrees of thermal degradation are shown in Figure 1. Holes and gaps created by thermal exposure present a threat to the wearer's respiratory protection through a possible drop in facepiece pressure and reduced air cylinder service time. Respiratory protection is compromised if the SCBA cannot maintain a higher facepiece pressure (inside the mask) than the ambient pressure (positive pressure) in the presence of a hole [34] or other deformation. If positive pressure is maintained after hole formation or other deformation induced leakage, the outward leakage causes an additional loss of cylinder air at a rate depending on factors such as facepiece pressure differential and leakage area. 

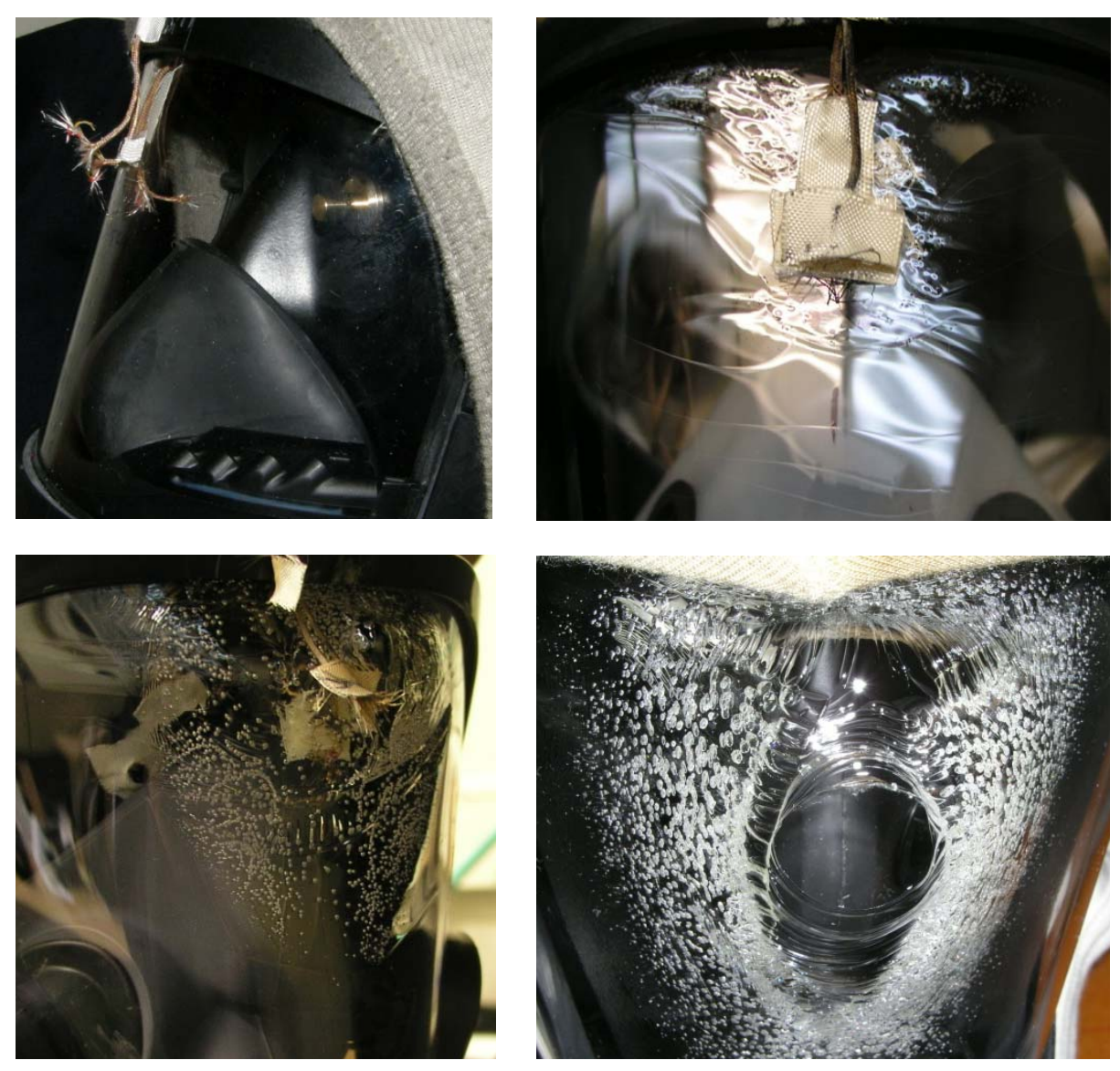

Figure 1 - Photos of example facepiece lenses; pre-exposure with the thermocouples placed on the lens (top left), post-exposure with cracks/crazing (top right), post-exposure with bubbling (bottom left), and postexposure with deformation causing a hole and bubbling (bottom right).

\section{UNCERTAINTY}

There are different components of uncertainty in the heat flux, temperature, flow rate, pressure, and time values provided in this report. Uncertainties are grouped into two categories according to the method used to estimate them. Type A uncertainties are those which are evaluated by statistical methods, and Type B are those which are evaluated by other means [35]. Type B analysis of systematic uncertainties involves estimating the upper $(+a)$ and lower $(-a)$ limits for the quantity in question such that the probability that the value would be in the interval $( \pm a)$ is approximately $95 \%$. For some of these components, uncertainties are derived from instrument specifications. Unless otherwise noted, uncertainty is reported in this study as expanded uncertainty, with a coverage factor of two, representing a confidence level of approximately $95 \%$. 


\section{EXPERIMENTAL SETUP}

Six models of SCBA facepieces, from five different manufacturers, were exposed to constant and repeatable levels of heat flux from a natural gas fired radiant panel apparatus as shown in Figure 2 and detailed in Appendix B. The facepiece models are identified by a letter from $\mathbf{A}$ through $\mathbf{F}$. Little difference in performance was expected between different facepieces, because all models have a $2 \mathrm{~mm}$ to $3 \mathrm{~mm}$ thick polycarbonate lens with relatively similar geometry.

The radiant panel apparatus consists of a vertically oriented refractory panel, heated by a premixed natural gas flame sheet on the surface of the panel. The panel has an approximate width of $31 \mathrm{~cm}$ (12 in) and an approximate height of $46 \mathrm{~cm}$ (18 in). The radiant panel source is described in detail in ASTM E162 Standard Test method for Surface Flammability of Materials Using a Radiant Heat Energy Source [36]. The air flow rate to the panel was approximately $434 \mathrm{~L} / \mathrm{min}(920 \mathrm{SCFH})$, and the natural gas flow rate was approximately $30 \mathrm{~L} / \mathrm{min}(63 \mathrm{SCFH})$. The hot combustion gases from the flame were pulled upward into a canopy hood above the apparatus with an exhaust flow rate of approximately $42 \mathrm{~m}^{3} / \mathrm{min}$ (1500 SCFM). As hot gases were directed upward into the hood, and the facepieces were located outside of the hot convective flow from the radiant panel, the heat transfer mechanism to the facepiece specimen was primarily radiative. Extraneous air flow in the room was controlled by closing doors and blocking sources of drafts to stabilize the flame during testing.

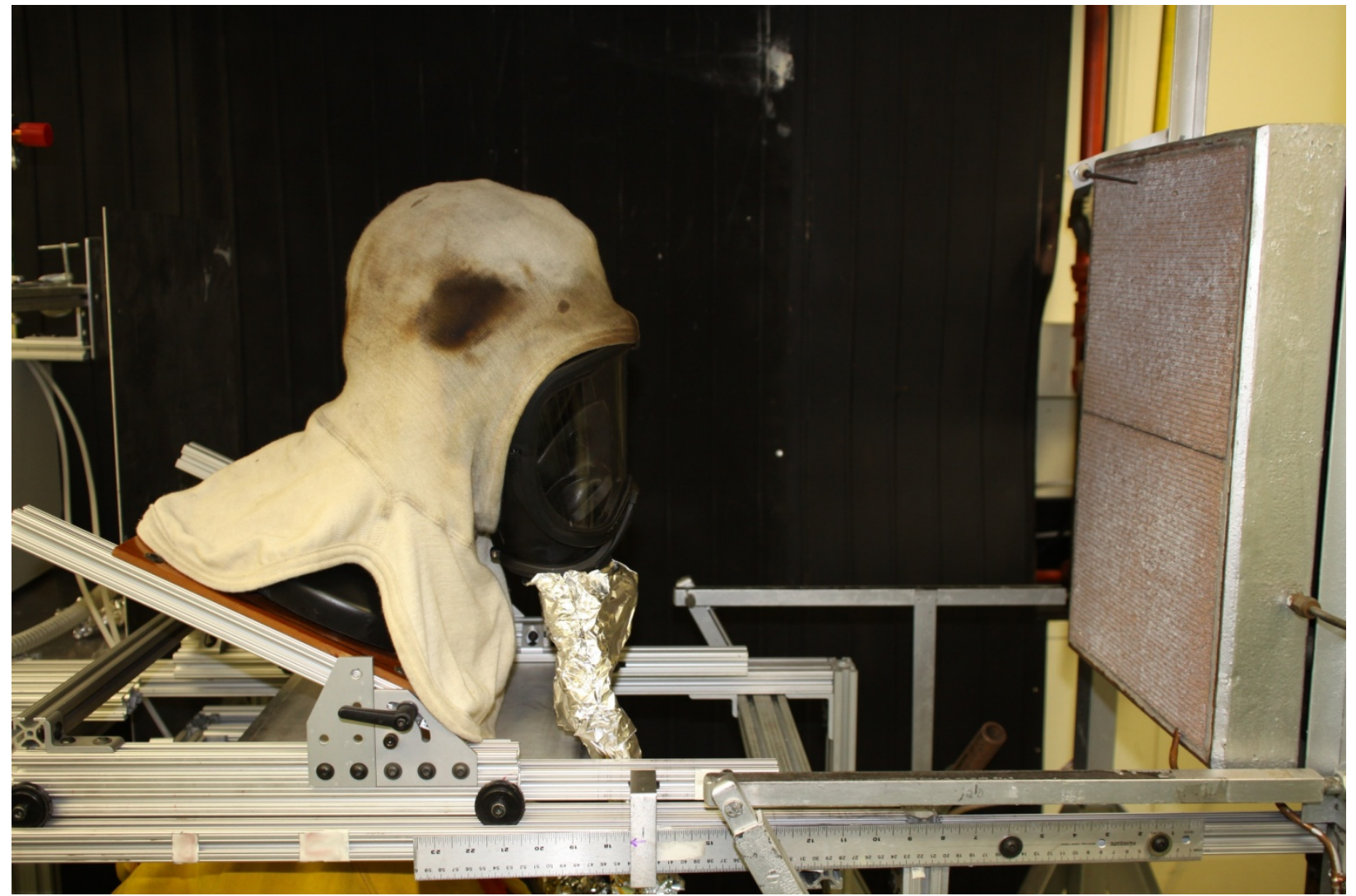

Figure 2. Radiant panel apparatus with SCBA facepiece and hood installed on adjustable headform frame. 
The facepieces were donned on a black polyurethane headform (Biosystems PosiChek3*) for SCBA air flow performance testing. The headform was attached to an aluminum base which was moved toward or away from the radiant panel along a horizontal track, as shown in Figure 2 and Appendix B. The aluminum base was locked over a range of angles for the purpose of making the vertical centerline of the facepiece lens parallel with the radiant panel. The headform, facepiece straps, seals, and regulator were covered by an aramid structural fire fighting protective hood for protection from radiant heat. For some SCBA geometries, the regulator and air supply hose were wrapped with aluminum foil for protection from repeated exposures. A three-layer aluminum shield with air gaps blocked heat from the radiant panel to the headform during panel warm-up, calibration, and set-up. The aluminum shield, as shown in Appendix B, was painted flat black on the side facing the radiant panel in order to absorb the incident radiant flux, rather than reflect it back to the panel, which affects the thermal equilibrium of the panel. The SCBA facepiece lens exposure began when the radiant shield was removed.

The heat flux incident on the facepiece was measured by a $2.54 \mathrm{~cm}(1.0$ in) nominal diameter water-cooled Schmidt-Boelter total heat flux gauge, aligned with the center of the radiant panel. The nominal design range of the heat flux gauge was $0 \mathrm{~kW} / \mathrm{m}^{2}$ to $20 \mathrm{~kW} / \mathrm{m}^{2}$, and the manufacturer reports a $\pm 3 \%$ calibration expanded uncertainty for these devices [37]. Results from an international study on total heat flux gauge calibration and response demonstrated that the expanded uncertainty of a Schmidt-Boelter gauge is typically $\pm 8 \%$ [38]. Providing a heat flux exposure to the facepiece that matched the heat flux measured by the transducer required careful placement and alignment of the heat flux gauge and the facepiece. A level and square were used to minimize errors, but each of the two alignments added an expanded uncertainty of approximately $\pm 1 \%$. In some cases, the facepiece geometry complicated the alignment, contributing an additional expanded uncertainty of about $\pm 1 \%$. Unsteadiness in the heat flux provided by the panel contributed an expanded uncertainty of approximately $\pm 2 \%$. The expanded uncertainty was calculated to be approximately $\pm 8 \%$ for the incident heat flux on the center of the facepiece lens. It is essential for the radiant panel to reach steady state prior to performing experiments or tests. For the apparatus used in this study, this process may take 45 min of continuous panel operation. In addition, due to the tendency of the flux from the radiant panels to drift, the radiant flux at the test position should be measured prior to, and after each experiment or test performed. If the radiant flux has drifted out of specification, the result should be noted, and experiment or test should be repeated.

Prior to an experiment, the heat flux gauge was moved along the horizontal track to locate the position (distance from the panel) with the desired level of heat flux. When the desired heat flux level was located, the position of the front of the gauge along the horizontal track was recorded, and the heat flux gauge was removed. A radiant heat flux of $15 \mathrm{~kW} / \mathrm{m}^{2}$ was realized at a perpendicular distance of approximately $178 \mathrm{~mm}(7.0 \mathrm{in})$ from the surface of the panel. The primary values of incident heat flux for the experiments were $5 \mathrm{~kW} / \mathrm{m}^{2}, 8 \mathrm{~kW} / \mathrm{m}^{2}, 10 \mathrm{~kW} / \mathrm{m}^{2}$, $12 \mathrm{~kW} / \mathrm{m}^{2}$, and $15 \mathrm{~kW} / \mathrm{m}^{2}$. The minimum heat flux was $5 \mathrm{~kW} / \mathrm{m}^{2}$, because below that exposure

\footnotetext{
* Certain commercial entities, equipment, or materials may be identified in this document in order to describe an experimental procedure or concept adequately. Such identification is not intended to imply recommendation or endorsement by the National Institute of Standards and Technology, nor is it intended to imply that the entities, materials, or equipment are necessarily the best available for the purpose.
} 
value, no thermal degradation was observed for test durations greater than 30 min. The maximum heat flux value chosen, $15 \mathrm{~kW} / \mathrm{m}^{2}$, resulted in observable degradation in less than one minute, but was far enough away from the radiant panel to be outside the panel induced convective flow.

Thermocouples were placed at six locations on and around the facepiece to measure air and surface temperatures. The standard uncertainty in the measured temperature of the thermocouple was $\pm 2.2{ }^{\circ} \mathrm{C}\left(4.0^{\circ} \mathrm{F}\right)$ below $293{ }^{\circ} \mathrm{C}\left(560 .{ }^{\circ} \mathrm{F}\right)$, and $\pm 0.75 \%$ at higher temperatures as determined by the manufacturer [39]. Small diameter thermocouples (approximately $0.5 \mathrm{~mm}$ diameter, made with $0.255 \mathrm{~mm}$ diameter wire, AWG 30, type K) were used to limit the impact of radiation and conduction on the temperatures reported by the thermocouples. The estimated total expanded uncertainty for facepiece temperature in these experiments was $\pm 15 \%$, due primarily to uncertainty in radiative heat transfer to the thermocouples. The locations of the thermocouples are described in Table 1.

Table 1. Thermocouple locations on and around the facepiece.

\begin{tabular}{lll}
\hline$T C$ & Location & Description \\
\hline 1 & Outside air & In the air just in front of the lens \\
2 & Lens ext. & On the outside surface of the lens \\
3 & Lens int. & On the inside surface of the lens \\
4 & Inside air & In the air between the lens and the headform \\
5 & Headform & On the surface of the headform \\
6 & Mouth air & In the air space in the mouth of the headform \\
\hline
\end{tabular}

The thermocouples were secured to the lens and the headform with high temperature fiberglass tape placed over the wire. The thermocouple wire was formed and shaped in order for the bead to touch the appropriate surface or air space. A mark was made along the vertical centerline of the lens, $4.5 \mathrm{~cm}$ ( $1.8 \mathrm{in}) \pm 0.2 \mathrm{~cm}(0.08 \mathrm{in})$ below the top edge of the exposed portion of the lens. This location was used for lens surface thermocouple placement for all facepieces. The air thermocouples were located $1.0 \mathrm{~cm}(0.4 \mathrm{in}) \pm 0.5 \mathrm{~cm}(0.2 \mathrm{in})$ away from the lens surface. The thermocouples installed near the facepiece lens are shown in Figure 1 and Figure 3. The location of the thermocouple installed on the headform surface is shown in Figure 4. 


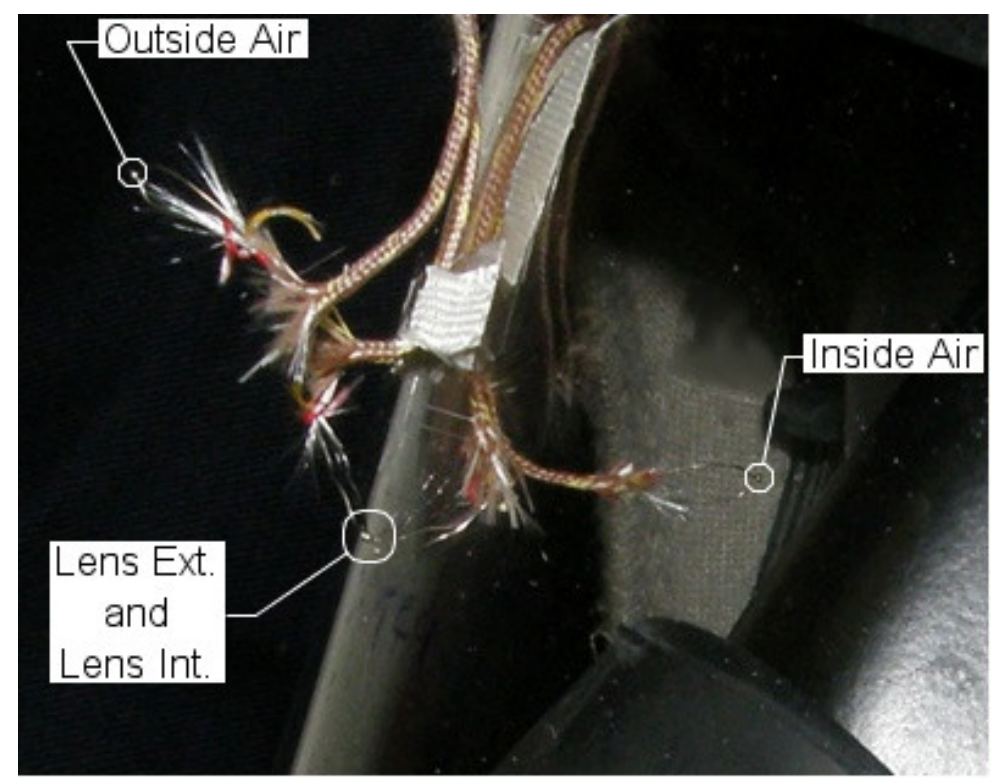

Figure 3. Facepiece lens thermocouples.

During some of the experiments, the surface thermocouple(s) moved off of the facepiece lens surface due to lens deformation and/or heat-induced failure of the adhesive component of the tape. In some cases, an FLIR/Inframetrics ThermaCAM PM350 infrared camera was used to obtain the surface temperature of the outside of the lens. The temperature range for the infrared camera was $100{ }^{\circ} \mathrm{C}\left(212{ }^{\circ} \mathrm{F}\right)$ to $290^{\circ} \mathrm{C}\left(554{ }^{\circ} \mathrm{F}\right)$. The lens emissivity was set to 1.0 , which provided approximately the same lens temperature as the thermocouple when measured at the same time, as discussed in Section 4 of this report. The interrogation area for the infrared measurement was located outside the region of radiant panel reflections from the facepiece lens. Expanded uncertainty in the infrared imaging temperature measurement is approximately $\pm 2 \%$ from manufacturer data [40]. The estimated expanded uncertainty was $\pm 15 \%$, including the emissivity uncertainty which was the result of assuming the facepiece lens had a blackbody emissivity of 1.0 .

The level of heat flux was measured inside the facepiece at the right eye location of the headform during some of the experiments. Heat flux was measured using a $0.64 \mathrm{~cm}(0.25 \mathrm{in})$ nominal diameter, Schmidt-Boelter type, water cooled, total heat flux transducer, with the measuring surface of the transducer installed approximately $1 \mathrm{~mm}(0.04 \mathrm{in})$ above the surface of the headform. The nominal operating range of the transducer was $0 \mathrm{~kW} / \mathrm{m}^{2}$ to $50 \mathrm{~kW} / \mathrm{m}^{2}$. The manufacturer reports a $\pm 3 \%$ calibration expanded uncertainty for these devices [37]. Results from an international study on total heat flux gauge calibration and response demonstrated that the expanded uncertainty of a Schmidt-Boelter gauge is typically $\pm 8 \%$ [38]. The location of the heat flux transducer in the headform is shown in Figure 4. 


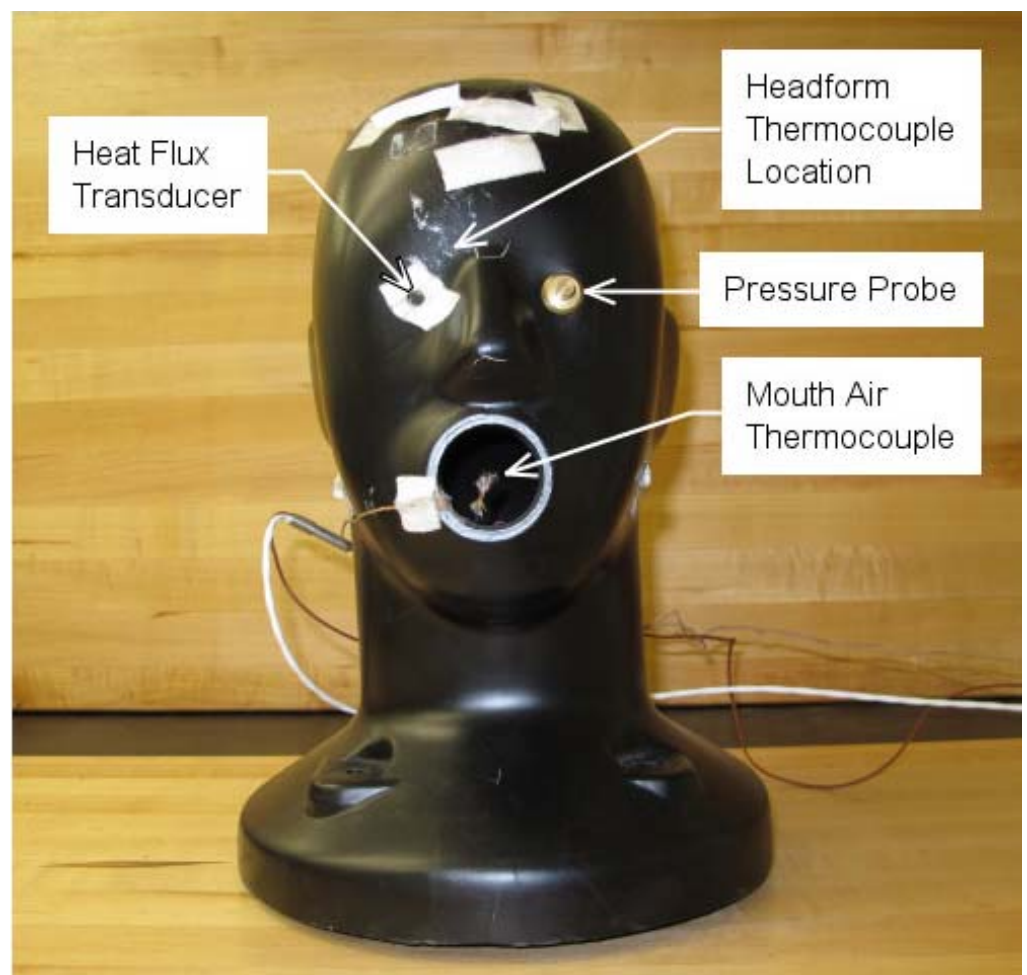

Figure 4. Headform with instrumentation locations.

Breathing was simulated in the facepiece using an ASL 5000 breathing machine manufactured by IngMar Medical. Previous SCBA thermal exposures had shown that a constant airflow in the facepiece had a cooling effect on the temperatures around the facepiece [33]. In the radiant panel experiments the breathing machine was programmed to reproduce both inhalation and exhalation of the $40 \mathrm{~L} / \mathrm{min}$ volume work rate breathing waveform specified by NIOSH and NFPA 1981 [16] at 24 breaths/min. The breathing machine generates the flow with the displacement of a piston, having an uncertainty of less than $\pm 1 \%$. The breathing machine is connected to the headform through a tube in the neck. Air was supplied to the facepiece from an air cylinder through the facepiece-mounted regulator in normal SCBA configuration. The SCBA regulator is designed to maintain a positive pressure in the facepiece during all phases of the breathing waveform. A pressure tap was located on the headform near the eye, with flexible tubing connecting the tap to a differential capacitance manometer for measurement of facepiece pressure during some of the experiments. The pressure transducer had an absolute range of $0 \mathrm{kPa}$ ( 0 torr) to $1.33 \mathrm{kPa}$ (10 torr). The manufacturer reports an expanded uncertainty of $\pm 0.15 \%$ with a coverage factor of three. Pressure, temperature, and heat flux data were sampled at a rate of $1 \mathrm{~Hz}$.

The performance of the facepiece lenses during the experiments was recorded on video in order to determine the times for cracks, bubbles and holes to form in the lens. The times of these events were obtained from the video footage with estimated expanded uncertainties of less than $\pm 3 \mathrm{~s}$. The time uncertainty resulted primarily from difficulties in determining the point at which lens degradation events occurred from examination of video images. Pressure measurements were also used to determine the time of hole formation with an estimated expanded uncertainty 
of $\pm 2 \mathrm{~s}$. The time uncertainty resulted primarily from the sampling rate $(1 \mathrm{~Hz})$ of the time varying pressure data.

\section{RESULTS AND DISCUSSION}

Temperatures of the six thermocouples on and around the facepiece are plotted as a function of time in Figure 5 for an exposure of $15 \mathrm{~kW} / \mathrm{m}^{2}$ incident on facepiece model $\mathbf{D}$. The lines represent data every $1 \mathrm{~s}$, but the symbols are shown every $25 \mathrm{~s}$ for clarity. The lens exterior temperature was the hottest surface temperature, followed by the lens interior temperature. At approximately $60 \mathrm{~s}$ into the test, the lens softened and began moving in and out with the inhalation and exhalation of the breathing cycle. Approximately $120 \mathrm{~s}$ into the test, the lens interior thermocouple temperature began to decrease, likely due to separation from the surface of the outwardly deforming lens. Shortly thereafter, at approximately $148 \mathrm{~s}$, a hole formed in the lens, and the exterior lens surface thermocouple temperature decreased. When the hole formed, air was forced out of the hole due to the positive pressure within the SCBA facepiece. The lens temperatures decreased due to the increased airflow through the facepiece as the SCBA regulator provided more air to maintain positive pressure within the mask. Due to the leak through the hole(s) in the lens, the SCBA air cylinder began to decrease pressure at a faster rate due to the increased flow of air to the mask. Increased airflow and cooling of the lens were observed in each facepiece that formed a hole. While the lens interior surface thermocouple appeared to detach from the surface, the exterior lens thermocouple appeared to stay in contact, as can be seen from the thermal imaging camera (TIC) temperature data (assuming an emissivity of 1.0) in Figure 5. The measured temperatures appear to plateau at approximately $125 \mathrm{~s}$ during the experiment, due to the TIC maximum temperature range setting of $290^{\circ} \mathrm{C}\left(550^{\circ} \mathrm{F}\right)$. 

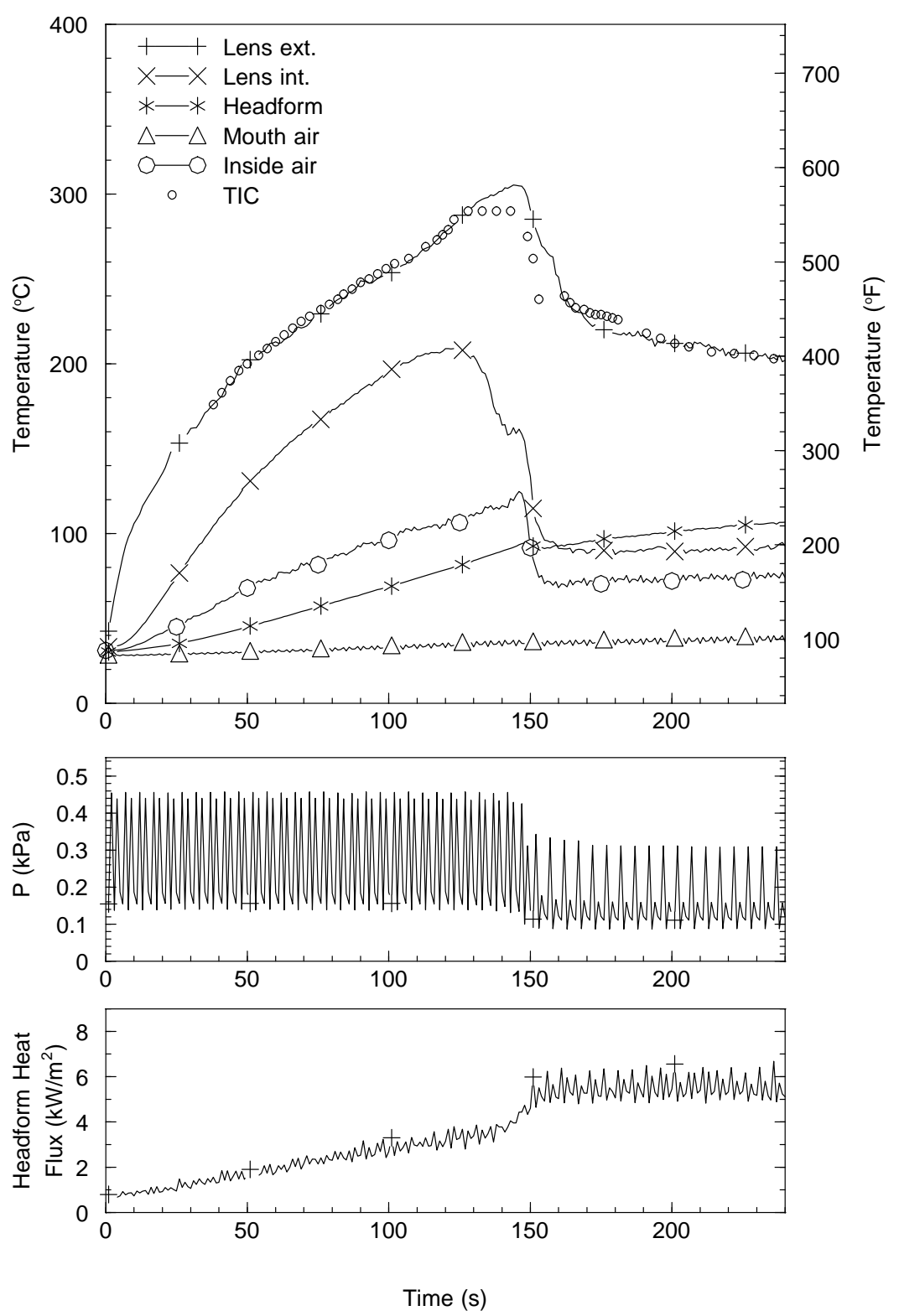

Figure 5 - Facepiece D thermocouple temperatures during a radiant panel exposure of $15 \mathrm{~kW} / \mathrm{m}^{2}$. A hole forms in the facepiece lens at approximately $148 \mathrm{~s}$ into the experiment.

Due to the connection between hole formation in the lens and increased airflow, recorded pressure data reveals the time of hole formation. The normal pressure profile without a hole can be seen in Figure 5, with a minimum value associated with inhalation and a maximum value associated with exhalation, with a nominal frequency of $0.4 \mathrm{~Hz}$ (24 breaths $/ \mathrm{min})$. When a hole formed at approximately $148 \mathrm{~s}$, there was a shift in the local minimum and maximum of the pressure wave profile. The size of the shift depended on the SCBA design and the geometry of the hole. Video observation confirmed a hole formed in the mask at this time. Identifying the time when a hole formed from the pressure data was more reliable than watching the video, 
because visual observation was limited by the orientation and contrast of the video recording. The pressure signal is also useful for determining when the SCBA is no longer able to provide breathing protection. Figure 6 shows the pressure inside a facepiece that has developed a hole, which is transitioning from positive pressure to negative pressure at approximately $600 \mathrm{~s}$. The pressure during inhalation first becomes negative at $598 \mathrm{~s}$ from the start of the experiment, as the air cylinder was no longer able to supply sufficient air to maintain positive pressure within the mask, typically when the cylinder supply was exhausted.

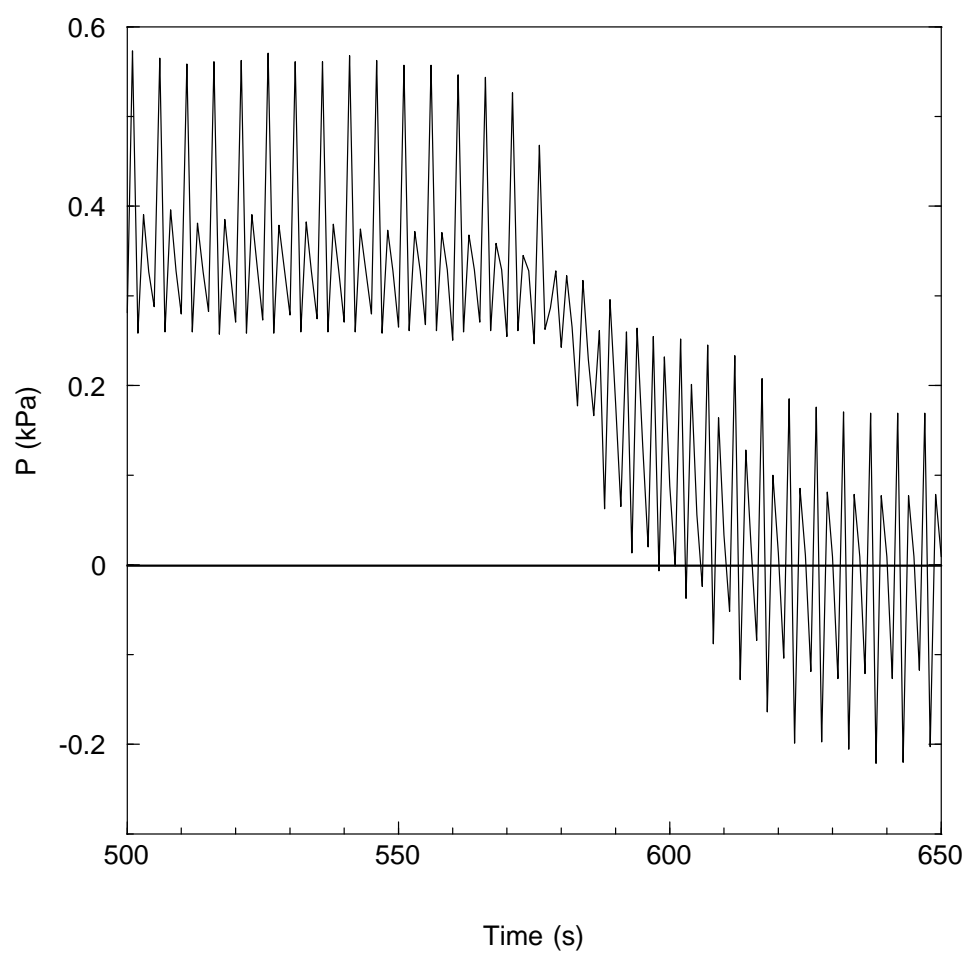

Figure 6. Pressure inside facepiece A during an experiment with radiant panel exposure of $15 \mathrm{~kW} / \mathrm{m}^{2}$. A hole forms in the facepiece lens at approximately $205 \mathrm{~s}$ into the experiment, and the pressure inside becomes negative during inhalation at approximately $600 \mathrm{~s}$.

Figure 5 shows the profiles of the headform temperature, air temperature in the mouth, and air temperature inside the facepiece. Although the headform temperature exceeded $100^{\circ} \mathrm{C}\left(21{ }^{\circ} \mathrm{F}\right)$ in the experiment, this does not translate directly into skin temperature as the headform surface and skin do not have the same thermal properties. The skin temperature of a wearer is expected to be lower due to the ability of the human body to dissipate heat through perspiration and circulation, a characteristic the headform does not possess. The mouth air temperature, which also follows the nominal breathing frequency of $0.4 \mathrm{~Hz}$ (24 breaths/min), remained cooler than the inside air temperature due to the flow of relatively cool breathing air supplied from the cylinder, which was largely isolated from the facepiece inside air by the nose cup. These trends are typical of the experiments in this study. 
The changes in the thermal conditions at the headform are also evident in Figure 5. At the time of hole formation, there is an increase in the heat flux measured at the headform inside the facepiece. In addition, the temperature of the headform surface thermocouple continued to increase after hole formation, although at a lesser rate. Analysis of the data did not uncover a trend in the behavior of headform heat flux or temperature after hole formation. This may be due to the variability in the location and characteristics of the holes and their spatial relationship to the single heat flux transducer and thermocouple installed on the headform. After a hole forms, the headform temperature and heat flux may increase, as shown in Figure 5 and Figure 8, or may decrease, as shown in Figure 7. Note that there is also periodicity in the heat flux data, due to the breathing air, with a nominal frequency of $0.4 \mathrm{~Hz}$ ( 24 breaths $/ \mathrm{min}$ ). The perodicity was due to the use of a total heat flux transducer, which was affected by convection from the movement of air within the facepiece.

In Table 2, the peak temperatures for each thermocouple around the facepiece at different levels of heat flux are averaged for the headform models tested. The mean, $\bar{x}$, standard deviation, $\sigma$, and number of experiments that are included, $\mathrm{n}$, are reported. In some cases, the lens exterior or interior temperature peak was not included in the mean because an accurate temperature reading was not available. This was the case when the thermocouple came off the surface at the beginning of the experiment and remained off the surface until the end. A thermal imaging camera (TIC) was used in some experiments to provide the lens exterior temperature data when the thermocouple came off the surface. The emissivity setting for the TIC was set to 1.0, and the range for the infrared (IR) detector was $100^{\circ} \mathrm{C}\left(212^{\circ} \mathrm{F}\right)$ to $290^{\circ} \mathrm{C}\left(550^{\circ} \mathrm{F}\right)$. The temperature was measured as close as possible to the location of the thermocouple. Note that the sample standard deviation of the lens exterior temperature for the $15 \mathrm{~kW} / \mathrm{m}^{2}$ experiments, as derived from statistical analysis of the data, was 8 times less for the TIC measurements as opposed to the thermocouple measurements. The results suggest that given the difficulty of performing thermocouple measurements on the deforming lens surface, infrared thermography (TIC) is a more effective method for temperature determination during these experiments. While there was good agreement between the thermocouple data and TIC data (Figure 5), more work is needed to better understand the use of infrared thermography in this application. Potential issues include, but are not limited to, lens emissivity values, directional effects, and wavelength dependence effects. 

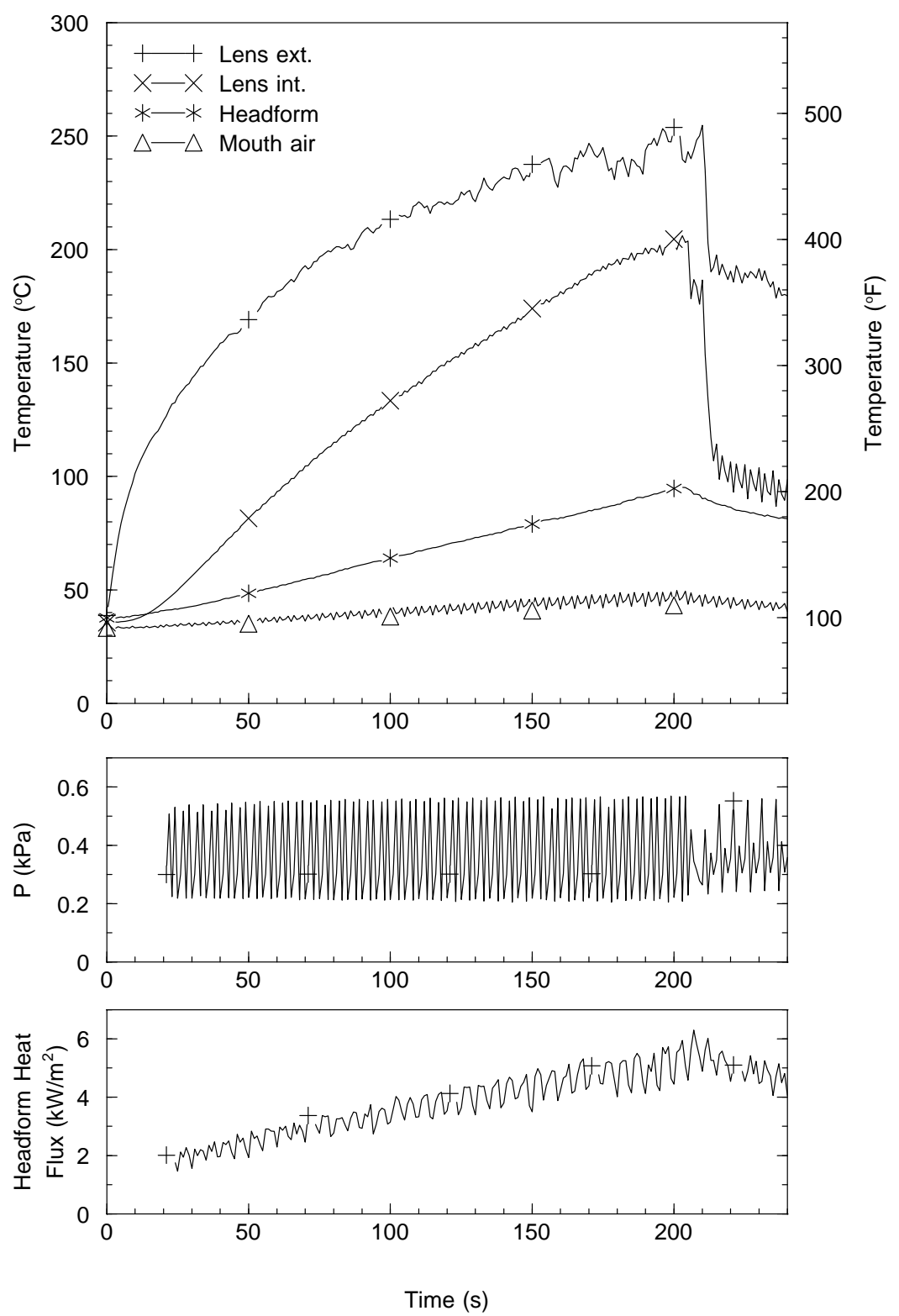

Figure 7. Facepiece A thermocouple temperatures during a radiant panel exposure of $15 \mathrm{~kW} / \mathrm{m}^{2}$. A hole forms in the facepiece lens at approximately $205 \mathrm{~s}$ into the experiment. 

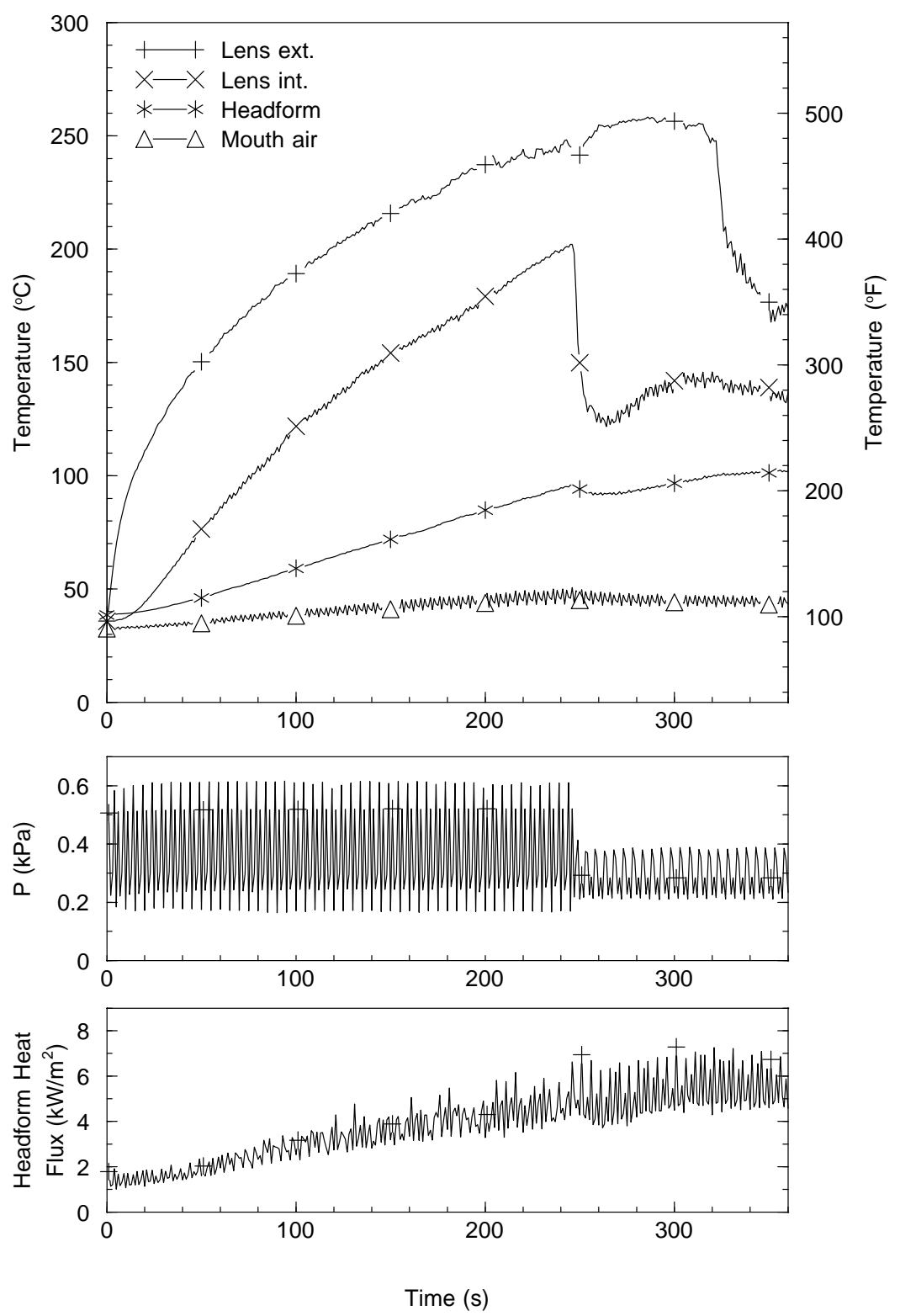

Figure 8. Facepiece A thermocouple temperatures during a radiant panel exposure of $12 \mathrm{~kW} / \mathrm{m}^{2}$. A hole forms in the facepiece lens at approximately $247 \mathrm{~s}$ into the experiment. 
The duration of the experiments varied depending on the time for the temperatures to reach a steady state or a hole to form, with a minimum duration of 5 min and a maximum duration of 20 min. As shown in Table 2, the outside air thermocouple temperature increased with heat flux. This was likely a result of increased radiative heat transfer from the radiant panel to the thermocouple as the heat flux increased. In all experiments, the lens exterior temperature was an order of magnitude or more lower than the radiant panel, and the lens was located outside the convective flow of the radiant panel, so radiative heating was the dominant mode of heat transfer to the lens. Radiation view factor effects are based on the spatial relationships between the facepiece, panel, and surroundings, and therefore the distance between the radiant panel and the facepiece must be consistent between experiments to provide repeatable results. The convective cooling component of heat transfer on the lens surface from air flow within the room and through the exhaust hood are functions of the test setup, and should also be controlled.

The lens exterior and interior temperatures increased for the most part with heat flux, except for the lens interior temperature at the $15 \mathrm{~kW} / \mathrm{m}^{2}$ exposure. This is likely due to the fact that most of these experiments formed holes in 2 min to $3 \mathrm{~min}$, which may have been before the interior temperature had an opportunity to reach steady state. There was also little difference between the peak inside air, headform, and mouth air temperatures at different heat fluxes. This is likely due to hole formation at higher heat fluxes, which provided a cooling effect and shortened the exposure.

Table 2 - Peak temperatures for the six thermocouples placed on and around the facepieces. Reported values are the mean, $\bar{X}$, sample standard deviation, $\sigma$, and number of experiments that are included, $n$.

\begin{tabular}{|c|c|c|c|c|c|c|c|c|c|c|c|c|c|c|c|c|c|c|}
\hline \multirow{2}{*}{$\begin{array}{l}\text { Heat } \\
\text { Flux, } \\
\mathrm{kW} / \mathrm{m}^{2}\end{array}$} & \multicolumn{3}{|c|}{$\begin{array}{l}\text { Outside Air, } \\
{ }^{\circ} \mathrm{C}\end{array}$} & \multicolumn{3}{|c|}{$\begin{array}{c}\text { Lens Exterior, } \\
{ }^{\circ} \mathrm{C}\end{array}$} & \multicolumn{3}{|c|}{$\begin{array}{c}\text { Lens Interior, } \\
{ }^{\circ} \mathrm{C}\end{array}$} & \multicolumn{3}{|c|}{$\begin{array}{l}\text { Inside Air, } \\
{ }^{\circ} \mathrm{C}\end{array}$} & \multicolumn{3}{|c|}{$\begin{array}{l}\text { Headform, } \\
{ }^{\circ} \mathrm{C}\end{array}$} & \multicolumn{3}{|c|}{$\begin{array}{c}\text { Mouth Air, } \\
{ }^{\circ} \mathrm{C}\end{array}$} \\
\hline & $\bar{x}$ & $\sigma$ & $\mathrm{n}$ & $\bar{x}$ & $\sigma$ & $\mathrm{n}$ & $\bar{x}$ & $\sigma$ & $\mathrm{n}$ & $\bar{X}$ & $\sigma$ & $\mathrm{n}$ & $\bar{X}$ & $\sigma$ & $\mathrm{n}$ & $\bar{x}$ & $\sigma$ & $\mathrm{n}$ \\
\hline 5 & 60 & 15 & 13 & 160 & 20 & 13 & 130 & 20 & 8 & 80 & 15 & 13 & 80 & 20 & 13 & 45 & 5 & 13 \\
\hline 8 & 85 & 30 & 6 & 210 & 15 & 5 & 180 & 10 & 4 & 105 & 15 & 6 & 105 & 20 & 6 & 50 & 10 & 6 \\
\hline 10 & 90 & 25 & 6 & 230 & 15 & 5 & 190 & 10 & 3 & 110 & 5 & 6 & 110 & 15 & 6 & 55 & 10 & 6 \\
\hline 12 & 95 & 30 & 6 & 250 & 10 & 4 & 210 & 20 & 3 & 105 & 15 & 6 & 100 & 20 & 6 & 50 & 5 & 6 \\
\hline 15 & 105 & 30 & 6 & 271 & 24 & 5 & 200 & 15 & 3 & 95 & 20 & 6 & 80 & 15 & 6 & 45 & 5 & 6 \\
\hline $15^{*}$ & - & - & - & 290 & 3 & 20 & - & - & - & - & - & - & - & - & - & - & - & - \\
\hline
\end{tabular}

*ens exterior temperatures measured with thermal imaging camera. No thermocouple installed on lens exterior.

For all levels of heat flux, the lens exterior thermocouple experienced the highest temperature, which increased for increasing levels of flux. In Figure 9, the lens exterior temperature rise of facepiece model $\mathbf{A}$ is shown for different levels of heat flux. As expected, the exterior facepiece lens temperatures increase more rapidly at higher imposed heat flux exposures. In addition, holes form more rapidly at higher heat fluxes. Holes were formed in approximately $206 \mathrm{~s}$ and $247 \mathrm{~s}$ for $15 \mathrm{~kW} / \mathrm{m}^{2}$ and $12 \mathrm{~kW} / \mathrm{m}^{2}$ fluxes, respectively, while no holes were formed at $5 \mathrm{~kW} / \mathrm{m}^{2}$ for the duration of a $1200 \mathrm{~s}$ exposure. The temperature plots for $15 \mathrm{~kW} / \mathrm{m}^{2}$ and $12 \mathrm{~kW} / \mathrm{m}^{2}$ stop when the facepiece exposures end at approximately $240 \mathrm{~s}$ and $313 \mathrm{~s}$, respectively. The thermocouples appear to have remained on the surface for the experiments plotted in Figure 9 until shortly after hole formation, with the $15 \mathrm{~kW} / \mathrm{m}^{2}$ thermocouple detaching from the surface at approximately $210 \mathrm{~s}$ and the $12 \mathrm{~kW} / \mathrm{m}^{2}$ thermocouple detaching at approximately $313 \mathrm{~s}$. For 
experiments run without the benefit of IR thermography, however, it may be difficult to differentiate between air flow cooling of the facepiece after hole formation and the thermocouple detaching from the surface.

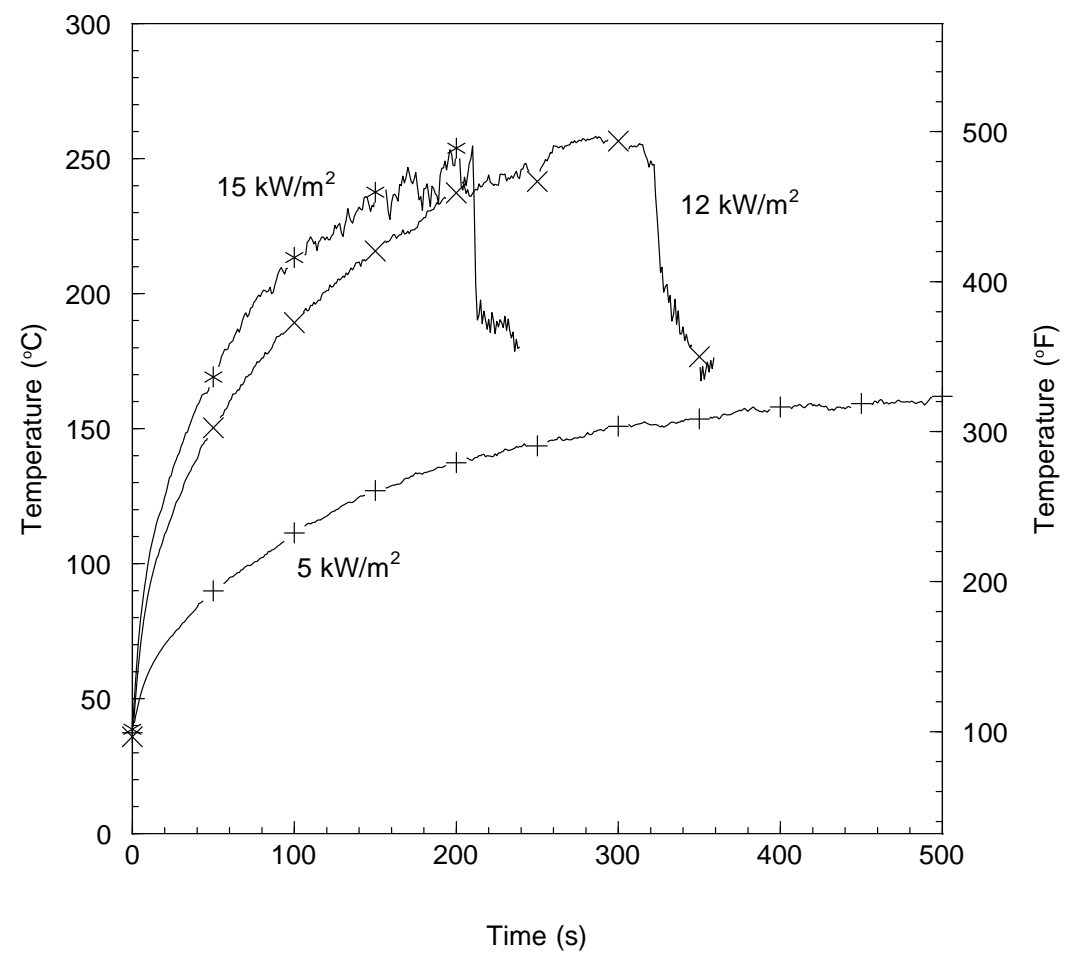

Figure 9 - Facepiece A lens exterior surface temperatures (via thermocouple) during radiant panel exposures of $5 \mathrm{~kW} / \mathrm{m}^{2}, 12 \mathrm{~kW} / \mathrm{m}^{2}$, and $15 \mathrm{~kW} / \mathrm{m}^{2}$.

To characterize facepiece lens performance, data were collected to measure the length of time until lens degradation appeared as a function of heat flux. Three main types of degradation were observed, cracks/crazing, bubbling, and hole forming, as pictured in Figure 1. Cracking and crazing appeared to be degradation on the surface, most likely caused by a difference in thermal expansion of the base material, polycarbonate, and the abrasion resistant coating. The cause of the bubbling is unknown, and could be desorption of water or products of pyrolysis. The times were determined from video and from the pressure data, in the case of hole formation. In Figure 10 the time for degradation is plotted as a function of the heat flux of the exposure. Different facepiece models are represented by differently shaped symbols. The figure shows the similarity of results for all facepieces tested, regardless of design or manufacturer. 


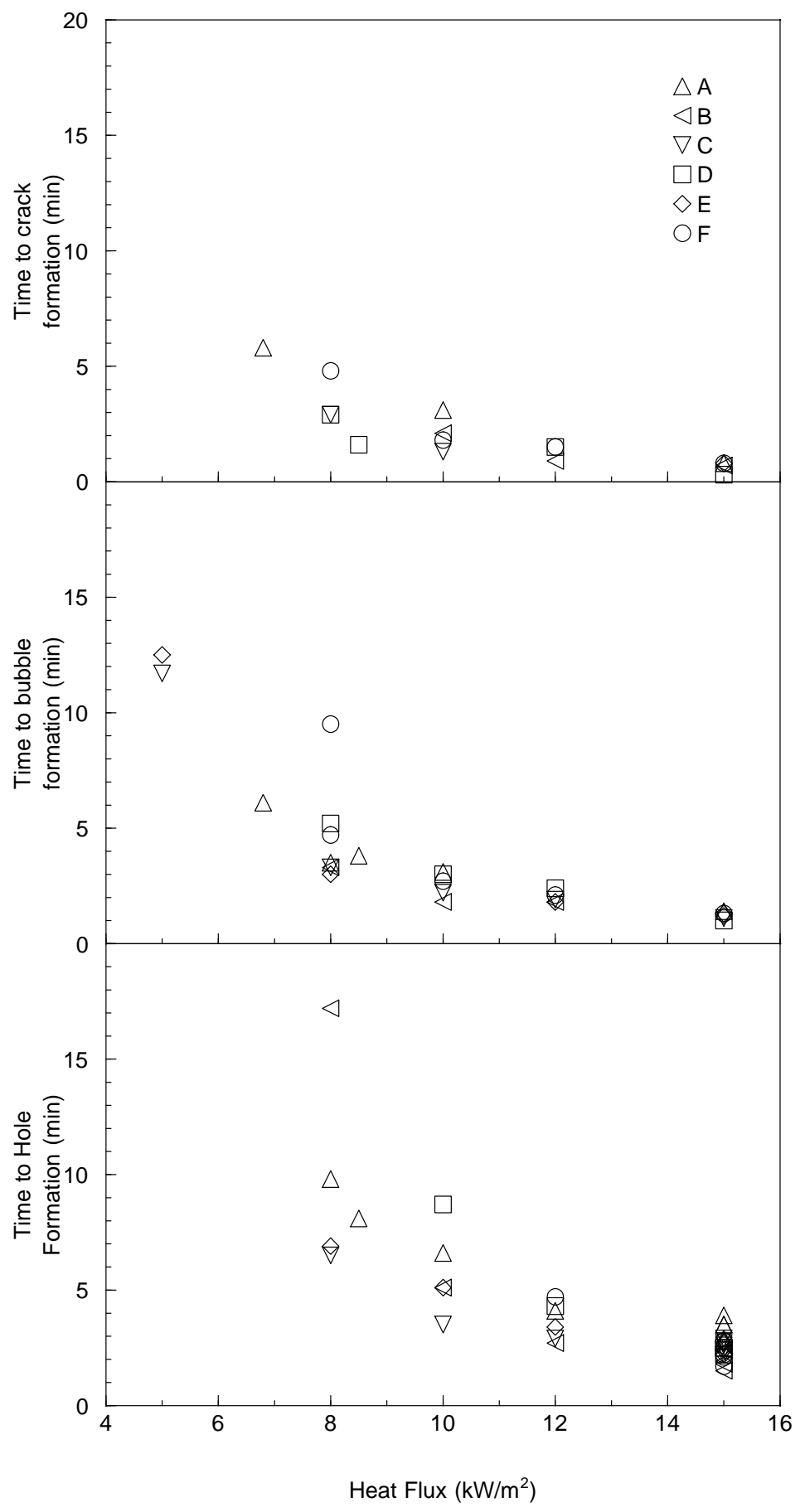

Figure 10 - Times for cracks, bubbles, and holes to develop plotted as a function of the exposure heat flux for six different facepiece models. 
Regardless of facepiece model, the length of time to each stage of degradation decreased as the heat flux was increased. For a specific level of heat flux, the cracks and crazing appeared first, followed by bubbling, and then holes. At $5 \mathrm{~kW} / \mathrm{m}^{2}$ for $20 \mathrm{~min}$, a few facepieces exhibited cracking and bubbling. Holes were not observed for any of the facepieces after $20 \mathrm{~min}$ of exposure at heat fluxes below $8 \mathrm{~kW} / \mathrm{m}^{2}$. For exposures of $8 \mathrm{~kW} / \mathrm{m}^{2}$ and above, all facepieces showed some thermal degradation in $20 \mathrm{~min}$. At the highest heat flux tested, $15 \mathrm{~kW} / \mathrm{m}^{2}$, holes formed between approximately $1.5 \mathrm{~min}$ and $3.9 \mathrm{~min}$.

Due to the similarity in the material and construction of the facepiece lenses, the time to hole formation was analyzed across all facepieces and plotted in Figure 11 parts (a) and (b). Both plots in the figure show the mean time for hole formation as a function of heat flux, with uncertainty bars representing Type A uncertainty with a coverage factor of two, representative of a confidence level of approximately $95 \%$. As the heat flux increased, the uncertainty in the results decreased. At a heat flux of $8 \mathrm{~kW} / \mathrm{m}^{2}$, the mean and uncertainty bars are different for Figure 11 (a) and (b). The dark uncertainty bars and rectangle shown in Figure 11 (b) represent the mean and uncertainty if the data point for the facepiece $\mathbf{B}$ experiment, which is approximately $125 \%$ greater than the mean of the other experiments, is excluded. The data is suspect because only one data point was available for facepiece $\mathbf{B}$ at this flux, and the data for facepiece $\mathbf{B}$ at other fluxes is typical of the other facepiece types. The larger set of uncertainty bars, shown in Figure 11 (a) include all of the data. While the uncertainty in the test results for all facepiece designs tested was smaller as the flux increased, the uncertainty remained approximately $50 \%$ of the mean over the range of heat fluxes examined. 


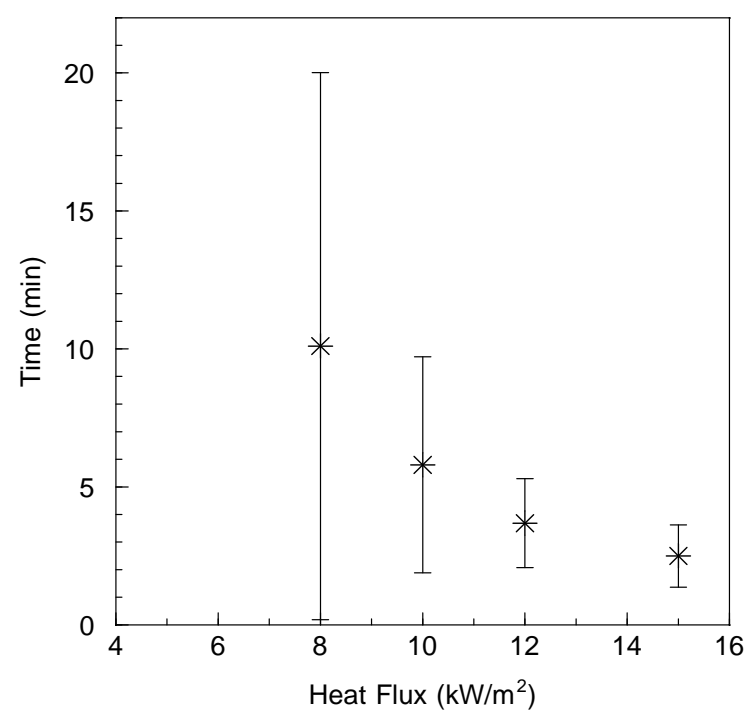

(a)

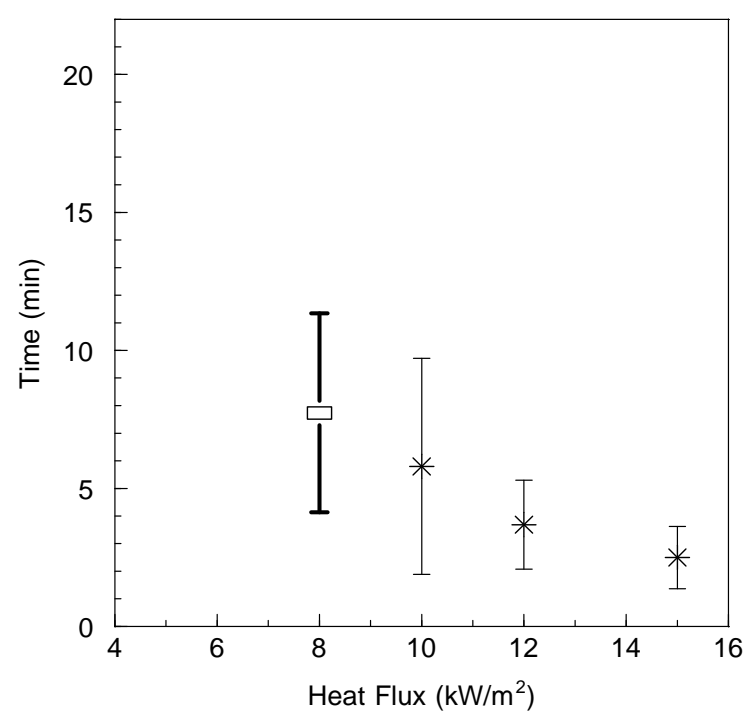

(b)

Figure 11. Mean hole formation time for all facepieces. Plot (a) includes all data, plot (b) excludes the one data point for facepiece $B$ at $8 \mathrm{~kW} / \mathrm{m}^{2}$.

The lens exterior temperature when cracks, bubbles, and holes appeared was found to be consistent regardless of exposure heat flux and facepiece model. The average temperature when cracks appeared for 25 experiments was $180{ }^{\circ} \mathrm{C}\left(356^{\circ} \mathrm{F}\right)$, with a sample standard deviation of $15^{\circ} \mathrm{C}\left(27^{\circ} \mathrm{F}\right)$. This temperature is close to the glass transition temperature of polycarbonate, approximately $150^{\circ} \mathrm{C}\left(302{ }^{\circ} \mathrm{F}\right)$. The average temperature when bubbles appeared for 42 experiments was $200^{\circ} \mathrm{C}\left(392^{\circ} \mathrm{F}\right)$, with a sample standard deviation of $25^{\circ} \mathrm{C}\left(45^{\circ} \mathrm{F}\right)$. The average temperature when holes appeared for 49 experiments was $270^{\circ} \mathrm{C}\left(518{ }^{\circ} \mathrm{F}\right)$, with a sample standard deviation of $25^{\circ} \mathrm{C}\left(45^{\circ} \mathrm{F}\right)$. This is close to the melting temperature of polycarbonate, approximately $300^{\circ} \mathrm{C}\left(572^{\circ} \mathrm{F}\right)$. 


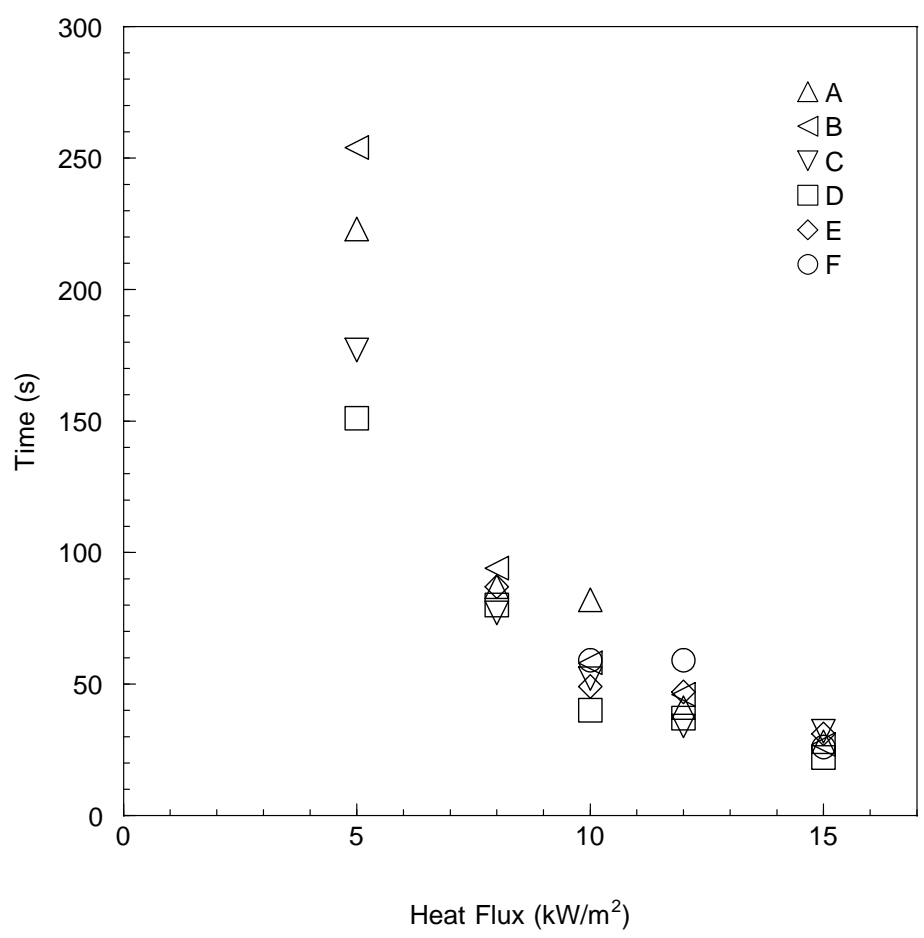

Figure 12. Time for facepiece lens exterior to reach $140^{\circ} \mathrm{C}\left(284^{\circ} \mathrm{F}\right)$.

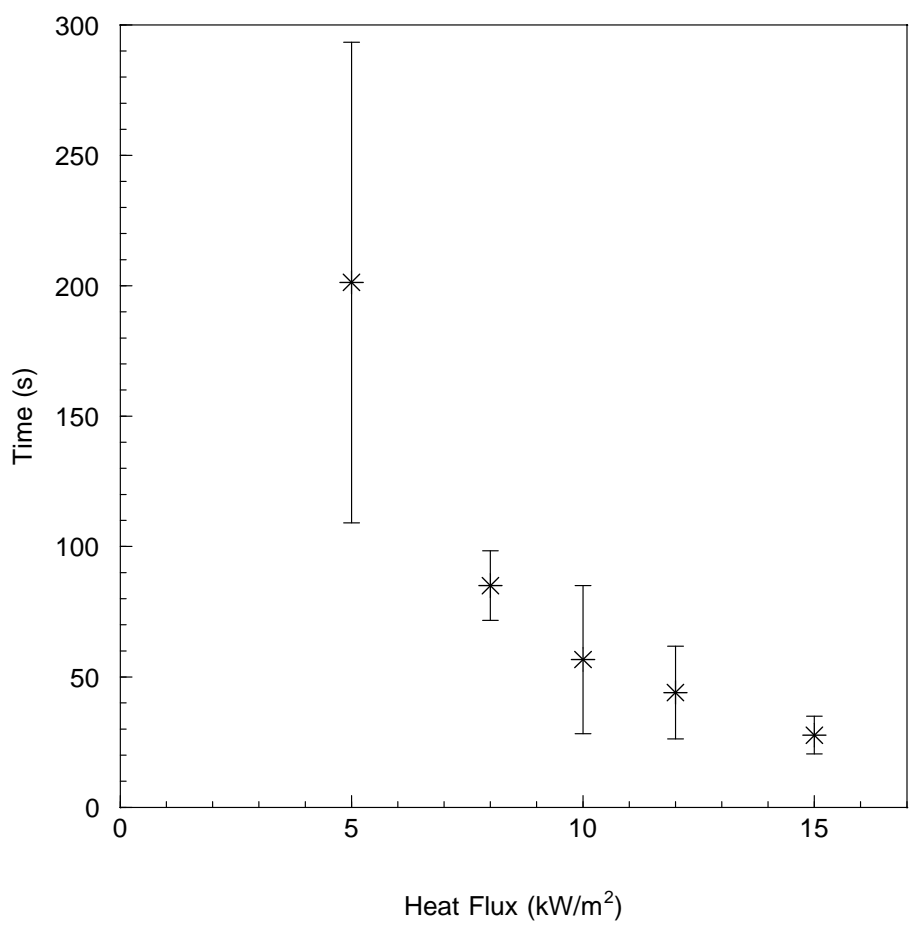

Figure 13. Mean time (for the data in Figure 12) for facepiece lens exterior to reach $140{ }^{\circ} \mathrm{C}\left(284^{\circ} \mathrm{F}\right)$. 
The times for the exteriors of the facepieces lenses to reach $140^{\circ} \mathrm{C}\left(284^{\circ} \mathrm{F}\right)$, which approaches the glass transition temperature of polycarbonate, are shown in Figure 12 and Figure 13. As the heat flux increases, the time to reach $140{ }^{\circ} \mathrm{C}\left(284^{\circ} \mathrm{F}\right)$ decreases, with the same trend for all facepieces. The times for all facepieces across all fluxes are similar, with the mean and uncertainty quantified in Figure 13. The uncertainty bars denote Type A uncertainty with a coverage factor of two, representative of a confidence level of approximately $95 \%$. The uncertainty in the mean time for the facepiece exterior to reach $140^{\circ} \mathrm{C}\left(284^{\circ} \mathrm{F}\right)$ shows a general decreasing trend as the incident heat flux increases, with the smallest absolute uncertainty at an incident heat flux of $15 \mathrm{~kW} / \mathrm{m}^{2}$. The results show the similarity of results for all facepieces tested, regardless of design or manufacturer.

\section{CONCLUSIONS}

The thermal performance of fire fighter SCBA facepiece lenses was studied by exposing facepieces mounted on a headform with simulated breathing air flow to constant levels of radiative heat flux from a gas-fired panel. Current fire fighter SCBA standards and certification in the United States do not require a radiant heat performance test, and therefore do not evaluate the equipment under the levels of radiative heat flux that fire fighters may encounter in fire fighting operations and training. The results from this study are limited to the performance of current SCBA lens technology to constant levels of radiant heat flux. Real exposures are typically a combination of radiant and convective heat flux, as well as exposure to environmental conditions, mechanical impacts, smoke deposition, and various other gas and water flows, which may affect lens degradation. When exposed to heat flux levels of $8 \mathrm{~kW} / \mathrm{m}^{2}$ and above for up to $20 \mathrm{~min}$, some facepiece lenses formed holes due to the combination of heating and positive pressure inside the facepiece. Holes formed between approximately 1.5 and 3.9 min at $15 \mathrm{~kW} / \mathrm{m}^{2}$. The temperature at the time when cracks, bubbles, and holes appeared on the lenses was consistent regardless of exposure heat flux and facepiece model. The average lens temperatures for cracks, bubbles and holes to form were approximately $180{ }^{\circ} \mathrm{C}\left(356{ }^{\circ} \mathrm{F}\right)$, $200{ }^{\circ} \mathrm{C}\left(392^{\circ} \mathrm{F}\right)$, and $270^{\circ} \mathrm{C}\left(518^{\circ} \mathrm{F}\right)$, respectively. Radiant heat flux exposure times leading to facepiece lens degradation, hole formation, and negative pressure are metrics that provide insight to the limits of SCBA performance in the thermal environments present during fire fighter operations.

An incident radiant heat flux of $15 \mathrm{~kW} / \mathrm{m}^{2}$ was determined to be a useful test criterion for determining the performance of SCBA facepiece lenses. This flux is representative of the flux experienced by fire fighters approaching the onset of flashover. Measurement of internal facepiece pressure was found to be a valuable method for determining the affect of holes on firefighter air supply duration and breathing protection. All of the SCBA facepieces tested exhibited holes in the lens in less than $5 \mathrm{~min}$ of exposure to $15 \mathrm{~kW} / \mathrm{m}^{2}$ of incident heat flux.

By providing data characterizing the performance of existing SCBA facepieces, the results of this and a previous study [33] have formed the basis for a new Radiant Heat Test in the 2013 draft edition of NFPA 1981 Standard on Open-Circuit Self-Contained Breathing Apparatus (SCBA) for Emergency Services [41]. This test exposes a breathing SCBA facepiece / headform 
to $15 \mathrm{~kW} / \mathrm{m}^{2}$ for $5 \mathrm{~min}$ in the radiant panel apparatus, followed by a $152 \mathrm{~mm}$ (6 in) drop test, and extended period of "breathing". The SCBA is required to provide positive pressure in the facepiece for a total of 24 minutes. In addition, the current Heat and Flame Test has been upgraded, subjecting the entire SCBA to a Heat Resistance Test in a convective circulating oven at $260{ }^{\circ} \mathrm{C}\left(500^{\circ} \mathrm{F}\right)$ for $5 \mathrm{~min}$, followed by direct flame contact.

\section{FUTURE WORK}

A future report will communicate the results of experiments performed with existing facepieces tested at $15 \mathrm{~kW} / \mathrm{m}^{2}$ according to the new radiant heat exposure test detailed in NFPA 1981 Standard on Open-Circuit Self-Contained Breathing Apparatus (SCBA) for Emergency Services - 2013 draft edition [41]. The performance metric for the test is the duration (time) that an SCBA is capable of providing positive pressure to the facepiece during and after a $5 \mathrm{~min}$ exposure to $15 \mathrm{~kW} / \mathrm{m}^{2}$ and a $152 \mathrm{~mm}$ (6 in) drop test. The pass / fail criterion is $24 \mathrm{~min}$.

Although much was learned about conditions associated with thermal degradation of SCBA facepiece lenses, more research and development are needed to understand the thermal degradation of facepiece lenses and to develop equipment that better resists the radiant heat fluxes encountered by the fire service during structure fires. 


\section{ACKNOWLEDGEMENTS}

The authors extend thanks to Roy McLane for his contributions and support, and to Scott Bareham for providing drawings of the experimental apparatus. The authors also acknowledge sponsorship in part by the Department of Homeland Security S \& T Directorate (POC Philip Mattson) and the US Fire Administration (POC William Troup). 


\section{REFERENCES}

[1] National Fallen Firefighters Foundation, National Fire Service Research Agenda Symposium, in Emmitsburg, MD (2005)

[2] M. Hirschler, Thermal Decomposition of Polymers, in SFPE Handbook of Fire Protection Engineering, P.J. DiNenno, ed. National Fire Protection Association, Quincy, MA (2008) 112-143.

[3] A. Schultz, PVT, Specific Heat, and Thermal Transitions, in Handbook of Polycarbonate Science and Technology, Marcel Dekker, Inc., New York, NY (2000) 149-178.

[4] J.R. Lawson, Fire Fighter's Protective Clothing and Thermal Environments of Structural Fire Fighting, NISTIR 5804, National Institute of Standards and Technology, Gaithersburg, MD, August 1996.

[5] R. Rossi, Fire Fighting and its Influence on the Body, Ergonomics 46, (10), 1017-1033 (2003).

[6] J.F. Krasny, J.A. Rockett, and D. Huang, Protecting Fire Fighters Exposed in Room Fires: Comparison of Results of Bench Scale Test for Thermal Protection and Conditions During Room Flashover, Fire Technology 24, (1), 5-19 (1988).

[7] A.M. Barowy and D. Madrzykowski, Thermal Behavior of Structural Fire Fighting Protective Ensemble Samples Modified With Phase Change Material and Exposed in FullScale Room Fires., NIST TN1739, National Institute of Standards and Technology, Gaithersburg, MD, March 2012.

[8] M.M. Schoppee, J.M. Welsford, and N.J. Abbott, Protection Offered by Lightweight Clothing Materials to the Heat of a Fire, ASTM STP 900, American Society for Testing and Materials, Philadelphia, PA, 1986.

[9] W.D. Walton, A.D. Putorti, W.H. Twilley, and J. Albers, Santa Ana Fire Department Experiments at South Bristol Street, NISTIR 5776, National Institute of Standards and Technology, Gaithersburg, MD, February 1996.

[10] J.B. Fang and J.N. Breese, Fire Development in Residential Basement Rooms, NBSIR 802120, National Bureau of Standards (currently NIST), Gaithersburg, MD, 1980.

[11] D. Madrzykowski and S. Kerber, Fire Fighting Tactics Under Wind Driven Conditions: Laboratory Experiments, NIST TN1618, National Institute of Standards and Technology, Gaithersburg, MD, January 2009.

[12] ISO 17492, Clothing for Protection Against Heat and Flame - Determination of Heat Transmission on Exposure to Both Flame and Radiant Heat, International Organization for Standardization, Geneva, Switzerland, 2003. 
[13] NFPA 1971, Standard on Protective Ensembles for Structural Fire Fighting and Proximity Fire Fighting, National Fire Protection Association, Quincy, MA, 2007.

[14] NFPA 1982, Standard on Personal Alert Safety Systems (PASS), National Fire Protection Association, Quincy, MA, 2007.

[15] NFPA 1801, Standard on Thermal Imagers for the Fire Service, National Fire Protection Association, Quincy, MA, 2010.

[16] NFPA 1981, Standard on Open-Circuit Self-Contained Breathing Apparatus (SCBA) for Emergency Services, National Fire Protection Association, Quincy, MA, 2007.

[17] A.K. Thiel, Special Report: Prevention of Self-Contained Breathing Apparatus Failures, USFA-TR-088, U.S. Fire Administration, Emmitsburg, MD, November 2001.

[18] NIOSH, Career Officer Injured During a Live Fire Evolution at a Training Academy Dies Two Days Later - Pennsylvania, Report F2005-31, National Institute of Occupational Health and Safety, Fire Fighter Fatality Investigation and Prevention Program, Morgantown, WV, September 2007.

[19] NIOSH, Career Lieutenant and Fire Fighter Die in a Flashover During a Live-Fire Training Evolution - Florida, Report F2002-34, National Institute of Occupational Health and Safety, Fire Fighter Fatality Investigation and Prevention Program, Morgantown, WV, June 2003.

[20] NIOSH, Career Fire Fighter Dies in Wind Driven Residential Structure Fire - Virginia, Report F2007-12, National Institute of Occupational Health and Safety, Fire Fighter Fatality Investigation and Prevention Program, Morgantown, WV, June 2008.

[21] NIOSH, A Volunteer Mutual Aid Captain and Fire Fighter Die in a Remodeled Residential Structure Fire - Texas, Report F2007-29, National Institute of Occupational Health and Safety, Fire Fighter Fatality Investigation and Prevention Program, Morgantown, WV, November 2008.

[22] NIOSH, Career Probationary Fire Fighter and Captain Die As a Result of Rapid Fire Progression in a Wind-Driven Residential Structure Fire - Texas, Report F2009-11, National Institute of Occupational Health and Safety, Fire Fighter Fatality Investigation and Prevention Program, Morgantown, WV, April 2010.

[23] NIOSH, Volunteer Fire Fighter Dies While Lost in Residential Structure Fire - Alabama, Report F2008-34, National Institute of Occupational Safety and Health, Fire Fighter Fatality Investigation and Prevention Program, Morgantown, WV, June 2009.

[24] D. Madrzykowski, Fatal Training Fires: Fire Analysis for the Fire Service, in International Interflam Conference, London, England (2007) 1169-1180.

[25] National Fire Fighter Near Miss Reporting System, Firefighter Experiences Near Miss in Flashover Trailer Training., Report 06-441, August 2006. 
[26] National Fire Fighter Near Miss Reporting System, Engine Crew Surprised by Sofa Flare Up., Report 06-428, August 2006.

[27] National Fire Fighter Near Miss Reporting System, Facepiece Damaged During Live Burn Training., Report 07-903, May 2007.

[28] National Fire Fighter Near Miss Reporting System, Problem With CAFS Unit Identified at Live Burn., Report 08-044, January 2008.

[29] A. Mensch and N.P. Bryner, Emergency First Responder Respirator Thermal Characteristics: Workshop Proceedings, NIST SP1123, National Institute of Standards and Technology, June 2011.

[30] National Fire Protection Association, NFPA ALERT NOTICE - SCBA Facepiece Lenses May Undergo Thermal Degradation When Exposed to Intense Heat., National Fire Protection Association, July 2012.

[31] J. Quintiere, Radiative and Convective Heating of Clear Plastic Fireman's Face Shield, NBS Report 10 885, National Bureau of Standards, Gaithersburg, MD, March 1972.

[32] B.J. Held and C.A. Harder, Effectiveness of Self-Contained Breathing Apparatus in a Fire Environment, Journal of the International Society for Respiratory Protection 1, (4), 9-27 (1983).

[33] A. Mensch, G. Braga, and N.P. Bryner, Fire Exposures of Fire Fighter Self-Contained Breathing Apparatus Facepiece Lenses, NIST TN1724, National Institute of Standards and Technology, Gaithersburg, MD, November 2011.

[34] R.A. Bryant and A. Mensch, Characterizing Inward Leakage in a Pressure-Demand, SelfContained Breathing Apparatus, Journal of Occupational and Environmental Hygiene 8, (7), (2011).

[35] B.N. Taylor and C.E. Kuyatt, Guidelines for Evaluating and Expressing the Uncertainty of NIST Measurement Results, NIST TN 1297, National Institute of Standards and Technology, Gaithersburg, MD, January 1994.

[36] ASTM E162-09, Standard Test Method for Surface Flammability of Materials Using a Radiant Heat Energy Source, ASTM International, West Conshohocken, PA, 2009.

[37] Medtherm Corporation Bulletin 118, (2003).

[38] W.M. Pitts, V.M. Annageri, J.L. de Ris, J.-R. Filtz, K. Nygard, D. Smith, and I. Wetterlund, Round robin study of total flux gauge calibration at fire laboratories, Fire Safety Journal 41, 459-475 (2006).

[39] Omega Engineering Inc., The Temperature Handbook, Stamford, CT (2004). p. Z-39-40. 
[40] FLIR Systems Inc., Limited Temperature Range in the P-Series Camera., (Dec. 2010). http://flir.custhelp.com/app/answers/print/a id/674/kw/accuracy. Accessed Dec. 2012.

[41] NFPA 1981, Standard on Open-Circuit Self-Contained Breathing Apparatus (SCBA) for Emergency Services - Post ROC Ballot Draft 2013 Edition, National Fire Protection Association, Quincy, MA, 2012. 


\title{
9. APPENDIX A - NFPA Alert Notice
}

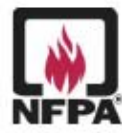

\author{
NFPA ALERT NOTICE
}

July 2,2012

\section{SCBA facepiece lenses may undergo thermal degradation when exposed to intense heat}

Safety Alert

Exposure to high temperature environments, which firefighters can encounter during fires they are attempting to extinguish, can result in the thermal degradation or melting of a Self- Contained Breathing Apparatus (SCBA) facepiece lens, resulting in elimination of the protection meant for the user's respiratory system and exposing the user to products of combustion and super heated air.

\section{Background}

SCBA is a critical component in the personal protective equipment (PPE) used by today's fire service. This equipment is essential for allowing firefighters to operate in hostile fire ground environments. However, in recent decades there have been significant changes in the environments encountered by structural firefighters and in how they operate in those environments.

- Structure fires involving modern building construction and furnishings produce significantly higher heat release rates than legacy buildings and their furnishings of earlier years, exposing firefighters to more rapid heat development and intense thermal conditions.

- PPE used by firefighters has evolved to provide enhanced overall thermal protection, allowing firefighters to remain in adverse conditions for longer time periods.

- Enhanced PPE for today's firefighters has made them less able to detect changing thermal conditions.

The SCBA facepiece lens is an integral part of SCBA and today the lens material is generally based on polycarbonate. The SCBA facepiece lens is often considered the weakest component of a firefighter's ensemble in high heat conditions, but the level of thermal performance of the facepiece lens has not been well understood.

During the investigation of firefighter fatalities that occurred from 2002 to 2011, the National Institute for Occupational Safety and Health (NIOSH) found evidence of thermal degradation of facepiece lenses that may have been a contributing factor in three fatalities. ${ }^{1}$ In the fatality cases, the firefighters were likely still "on air" at the time they were overrun by extreme thermal conditions; all had their SCBA facepiece still in place; all had SCBA facepieces that displayed extensive damage consistent with thermal conditions that likely exceeded the capabilities of the SCBA facepiece lens, resulting in the loss of respiratory protection from an Immediately Dangerous to Life and Health (IDLH) environment. The firefighters in these incidents suffered thermal injuries to their respiratory system and sustained inhalation injuries from products of combustion.

$\mathrm{NIOSH}$ also reported on the investigation of three SCBA from a state training academy ${ }^{2}$ where the SCBA facepiece lens showed evidence of thermal degradation after being used in live fire training. Additionally, in four other NIOSH Line of Duty Death Investigations ${ }^{3}$, the evidence, while not conclusive was suggestive of possible SCBA degradation or failure.

Among the voluntary consensus standards developed by the National Fire Protection Association (NFPA) are standards for firefighter personal protective clothing and equipment. These include NFPA 1981, Standard on Open-Circuit Self-Contained Breathing Apparatus (SCBA) for Emergency Services, which is principally developed by NFPA's Technical Committee on Respiratory Protection Equipment (the Technical Committee). The concerns with facepiece lenses identified in the NIOSH investigations were brought to the attention of the NFPA Technical Committee by the National Institute of Standards and Technology (NIST) and the NIOSH Division of Safety Research, Fire Fighter Fatality Investigation and Prevention Program.

In addition, in 2010 NIST, NIOSH, the Fire Protection Research Foundation (FPRF) and the NFPA jointly hosted a research planning workshop on evaluating and addressing the concerns regarding the thermal impact of SCBA facepiece lenses. "Subsequently, the United States Fire Administration (USFA) funded and participated with NIST in research ${ }^{5}$ that validated the adverse consequences to firefighters when lens degradation occurs in extreme thermal conditions and developed and provided new testing and performance methodologies to the NFPA Technical Committee on Respiratory Protection Equipment. ${ }^{6}$ Based on the information learned from the NIOSH investigations and NIST research, this Technical Committee is in the

For further information, visit www.nfpa.org /scba and www.cdc.gov/niosh/fire 
process of incorporating new test methods and performance and criteria for facepiece lenses into the proposed 2013 edition of NFPA 1981, which is slated for completion and issuance as early as the Fall of 2012. Information on the continuing development of this new edition is available at http://www.nfpa.org/1981next.

\section{NFPA Recommends}

- $\quad$ SCBA facepiece lenses showing evidence of exposure to intense heat is an indication of thermal degradation and potential failure. In addition to complying with the Inspection, Repair and Removal from Service provisions of NFPA 1852, Selection Care and Maintenance of Open-Circuit SelfContained Breathing Apparatus, fire departments, fire academies, and emergency service organizations should ensure that all SCBA facepiece lenses are inspected before and after each use. Any SCBA facepiece lens found to have cracks, crazing, bubbling, deformation, discoloring, gaps or holes should be immediately removed from service and a replacement issued.

- In addition to complying with the provisions of NFPA 1404, Standard for Fire Service Respiratory Protection Training, fire departments, fire training academies and emergency service organizations should review their training programs to ensure that the following components are addressed in their curriculum: the lim itations of respiratory protection devices; awareness that delayed recognition of intense thermal environments that can occur while wearing a firefighter protective ensemble; and how to respond to problems encountered when using SCBA in high temperature environments.

- When evaluating fire conditions and determining fire attack tactics and strategies, incident comm anders, company officers, and firefighters should take into account the thermal performance limitations of SCBA facepiece lenses and the problem of delayed recognition of heat intensity due to the thermal insulation/protection provided by the PPE ensemble.

- In addition to following existing departmenta Standard Operating Procedures and Guidelines regarding use of PPE, all personnel engaged in commanding, supervising or performing interior fire attack operations can reduce the possibility of facepiece lens deterioration or failure by maintaining constant situational awareness and by being alert for deteriorating conditions indicative of extreme thermal temperatures/flashover conditions. When confronted with such conditions, personnel must initiate self-evacuation or be directed to retreat to a safe area.

- Fire departments, fire academies, and emergency service organizations that utilize SCBA should begin planning for the upgrade or replacement of current SCBA facepiece lenses with products compliant with the upcoming 2013 edition of NFPA 1981.

Even after the issuance of the new edition of NFPA 1981 , it is expected that there will be continued research and development activities to better understand the thermal characteristics of SCBA facepiece lenses, and to better predict the conditions that are likely to cause a SCBA facepiece lens failure. As updated information becomes available, it will be posted at www.nfpa.org/scba.

$$
\text { ******* }
$$

Additional resources on firefighter safety can be found at:

The Fire Ground Survival Program developed by the International Association of Firefighters (IAFF), www.iaff.org/HS/FGS/FGSIndex.htm, and

Rules You Can Live By, Rules of Engagement for Firefighter Survival published by the International Association of Fire Chiefs, (IAFC), www.iafcsafety.org/downloads/ROE_Poster_fFINAL.pdf

Career officer LODD as instructor at training facility, Pennsylvania, 2005 (NIOSH Report F2005-31); Career officer and fire fighter at residential fire, Texas, 2009 (NIOSH Report F2009-11). Volunteer fire fighter killed by rapid fire progression in apartment complex - Maryland (NIOSH Report F201102 ).

Status Investigation Report of Three Self-Contained Breathing Apparatus Submitted by the Pennsylvania State Fire Academy, Lewistown, Pennsylvania NIOSH Task No. 14292, May 1, 2007.

Career officer and fire fighter LODD at acquired structure training, Florida, 2002 (NIOSH Report F2002-34); Volunt eer officer and fire fighter LODD at residential fire, Texas, 2007 (NIOSH Report F2007-29);

Career fire fighter LODD at residential fire, Virginia, 2008 (NIOSH F2007-12); Volunteer fire fighter LODD at residential fire, Alabama, 2008 (NIOSH Repor F2008-34)

Bryner N. and Mensch A., "Emergency First Responder Respirator Therma Characteristics: Workshop Proceedings," Workshop held in Pittsburgh, PA in July 2010, NIST Special Publication 1123, Gaithersburg MD, June 2011.

Bryner N., Braga G. and Mensch A., "Fire Exposures of Fire Fighter SelfContained Breathing Apparatus Facepiece Lenses," NIST Technical Note 1724, National Institute of Standards and Technology, Gaithersbure,MD, November 2011

${ }^{6}$ Report on Proposals, (F12), NFPA 1981 Standard on Open- Circuit SelfContained Breathing Apparatus (SCBA) for Emergency Services, Log \#CP5, Log \#CP 6

For further information, visit www.nfpa.org /scba and www.cdc.gov/niosh/fire 
10. APPENDIX B - Apparatus Drawings and Images
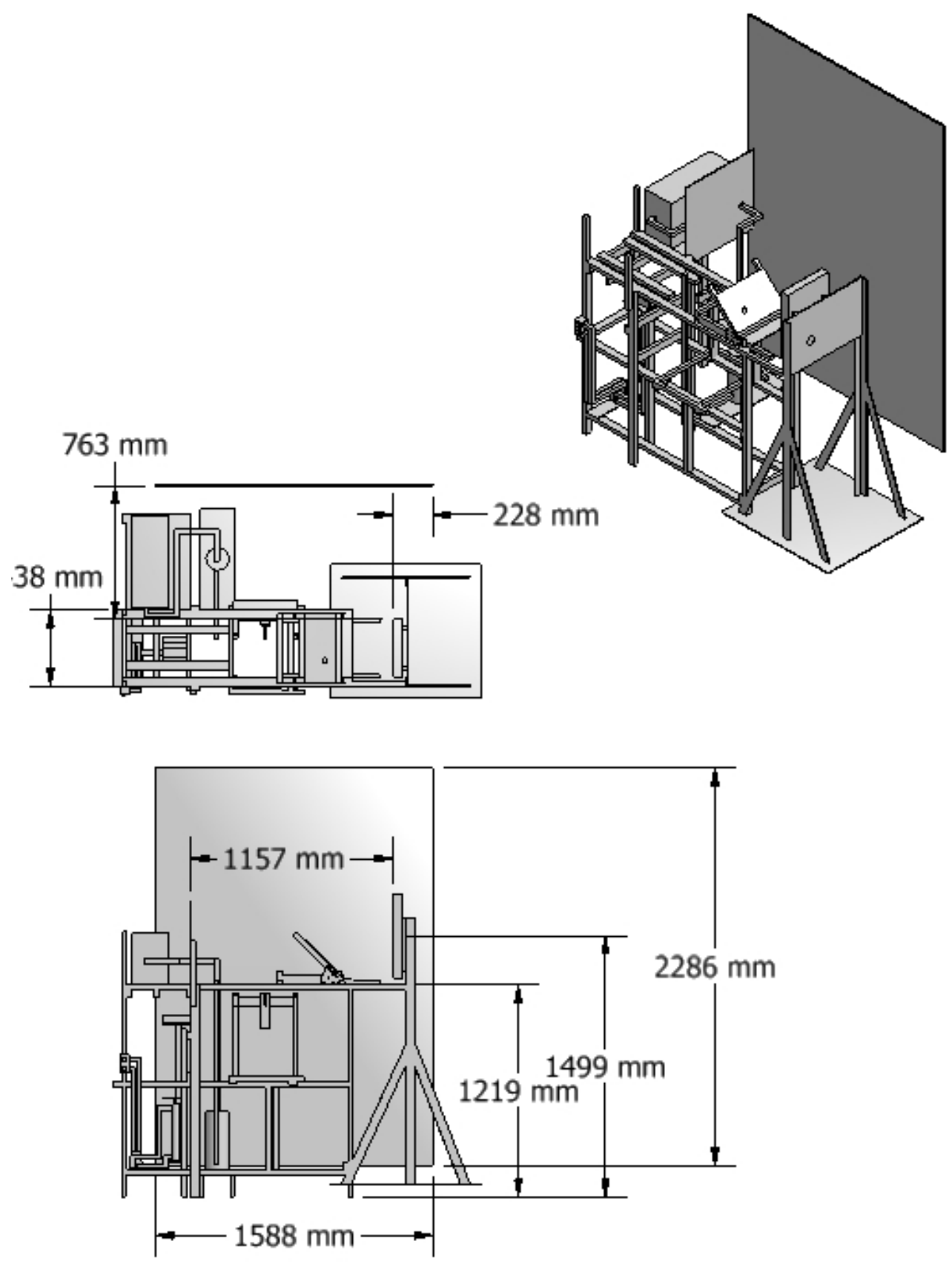

Figure 14. Radiant panel apparatus with headform cart installed. Isometric view (top), plan view (middle), and elevation view (bottom). 


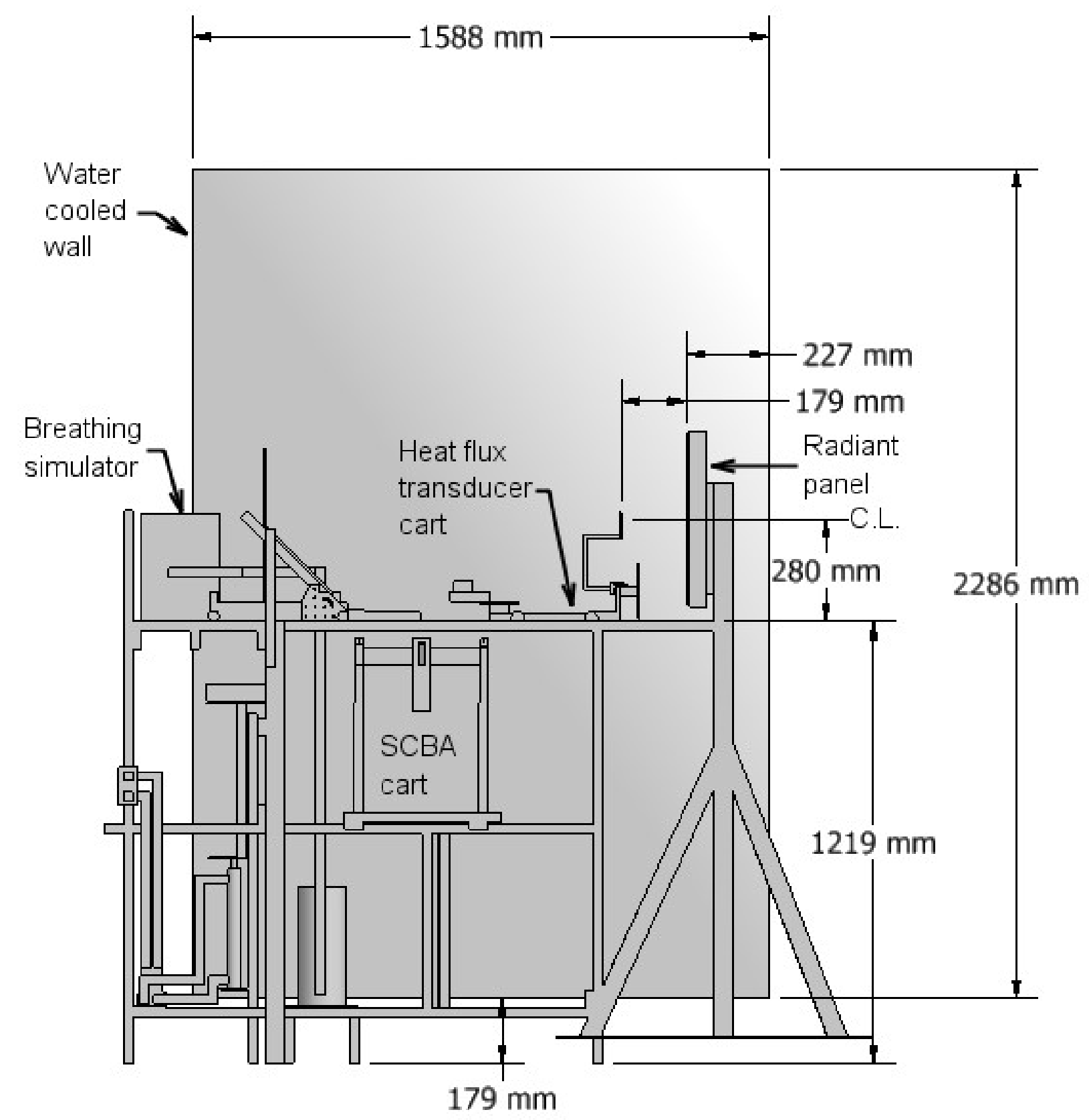

Figure 15. Radiant panel apparatus, elevation view. Heat flux transducer centerline (C.L.) aligned with centerline of gas fired radiant panel. Exhaust hood installed over entire apparatus, not shown. 


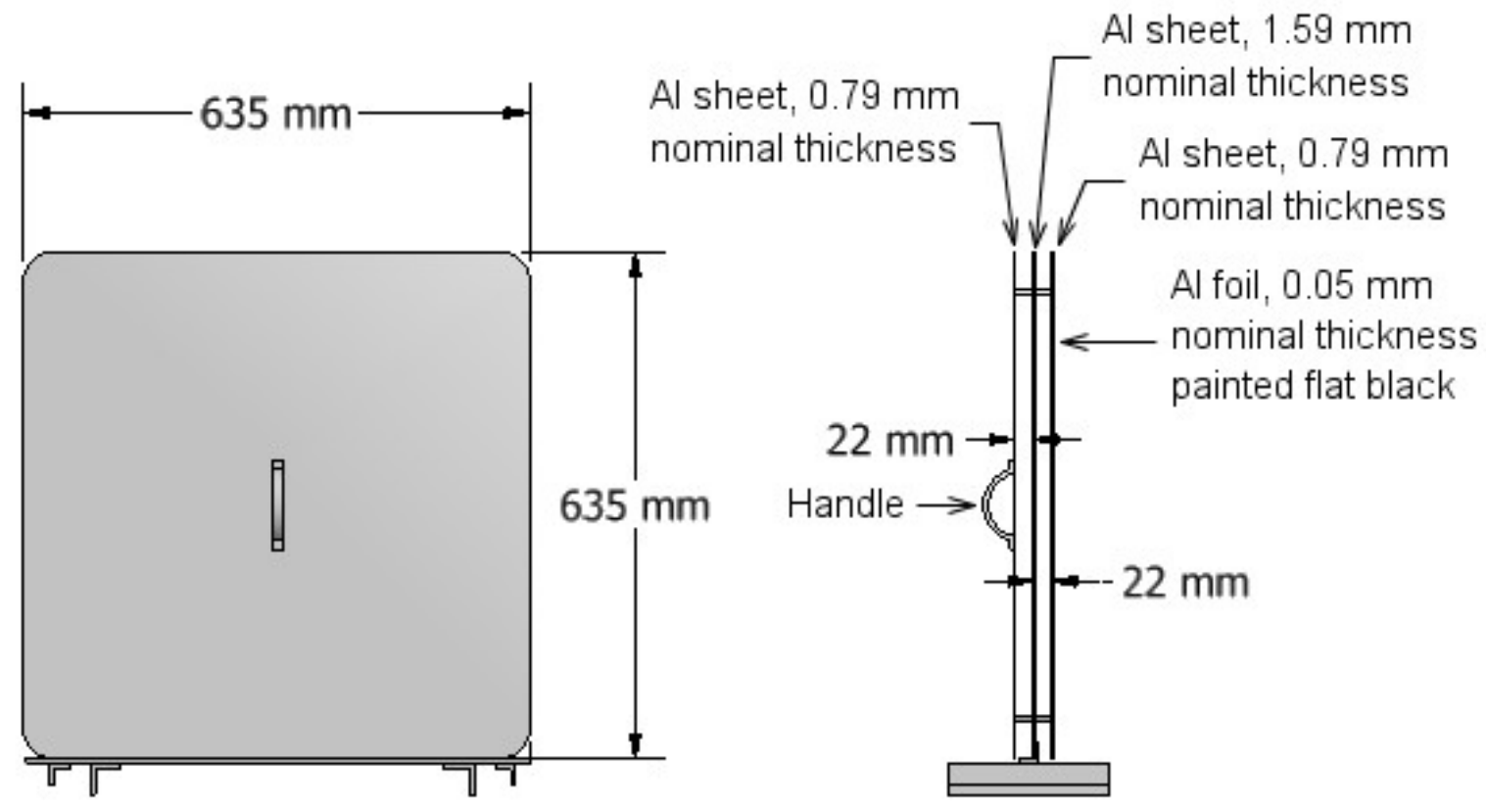

Figure 16. Radiant heat shield. 

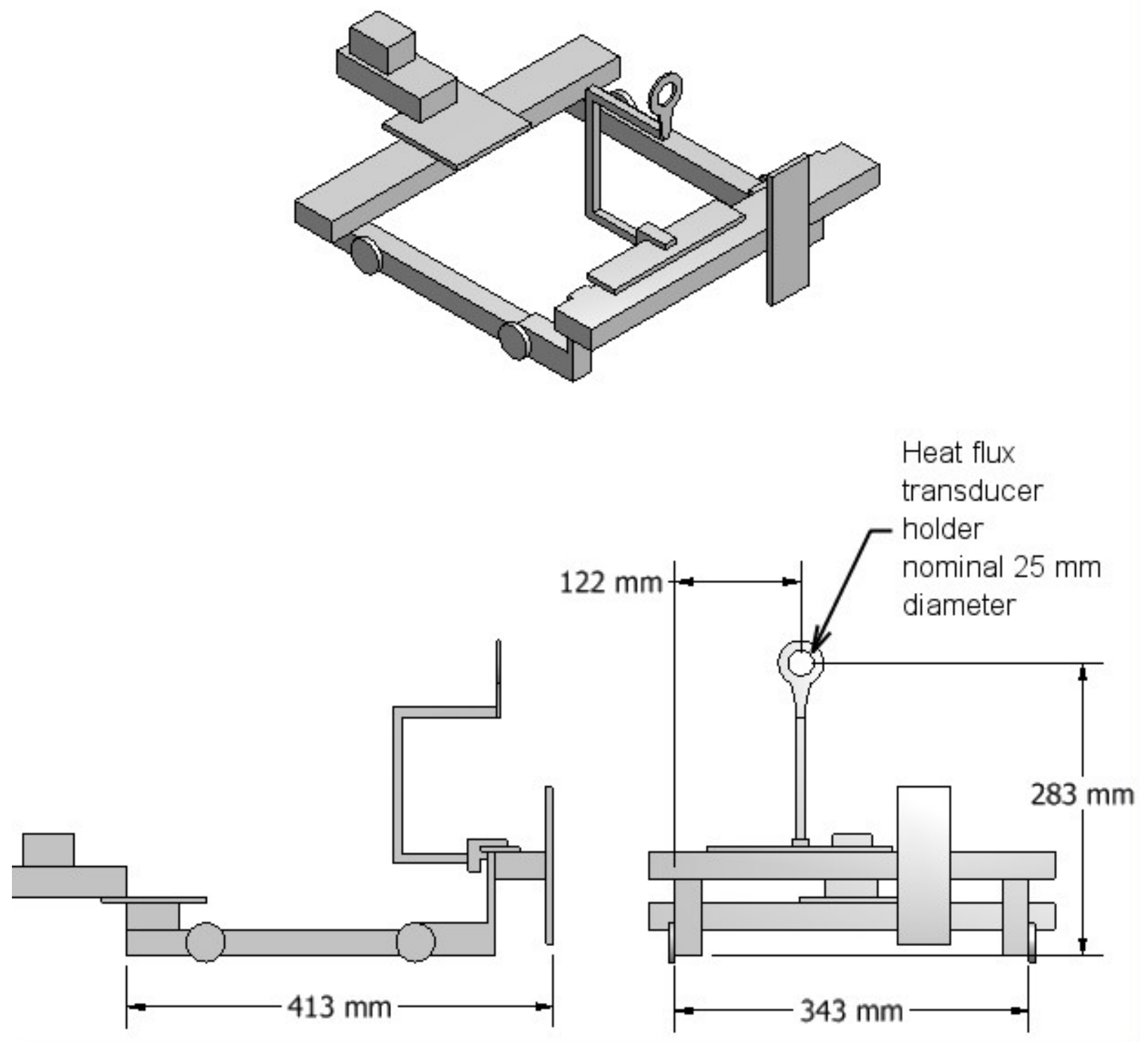

Figure 17. Heat flux transducer cart. Centerline of heat flux transducer passes through horizontal and vertical center of the face of the radiant panel. Transducer not shown. 

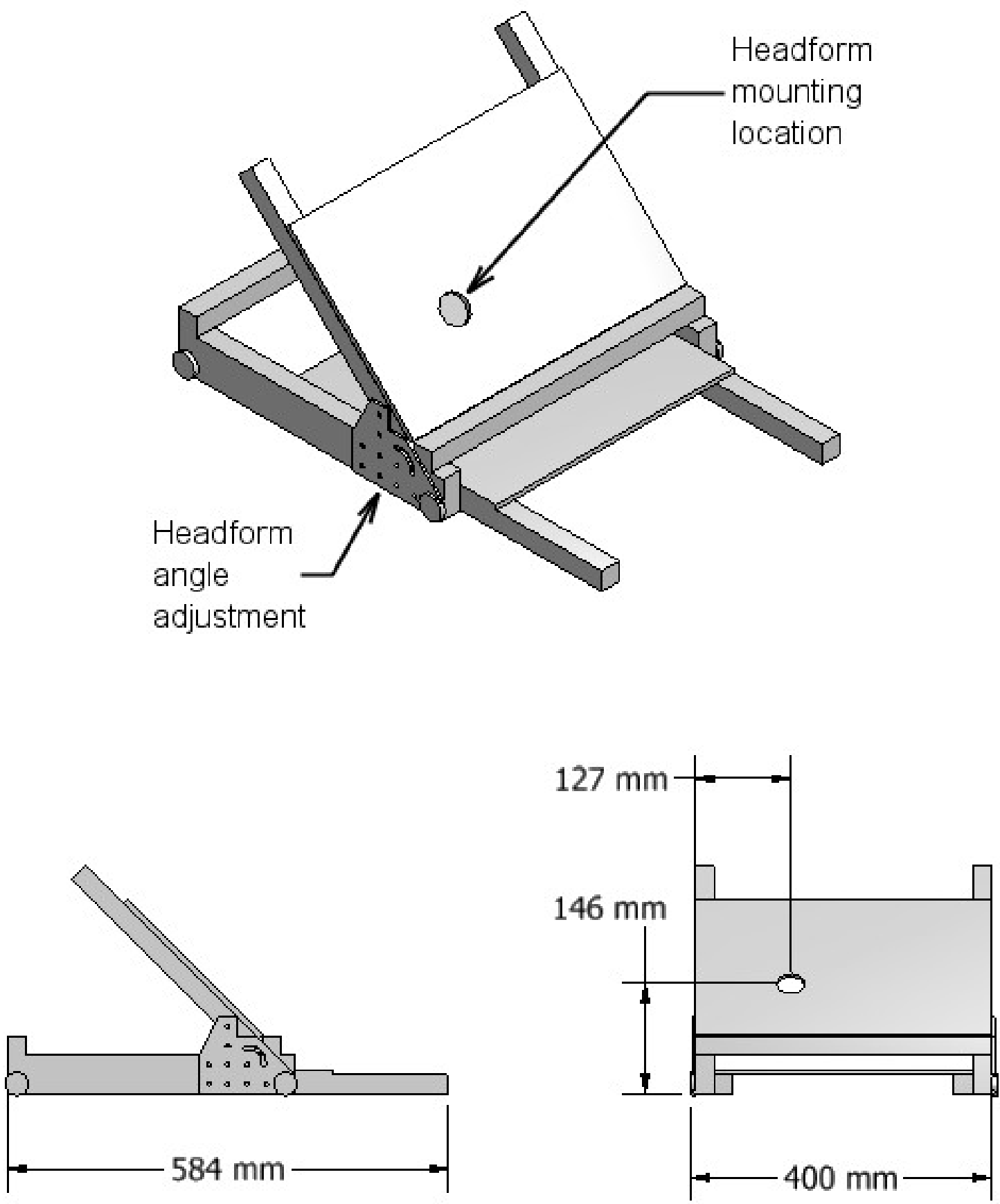

Figure 18. Headform and facepiece cart. 

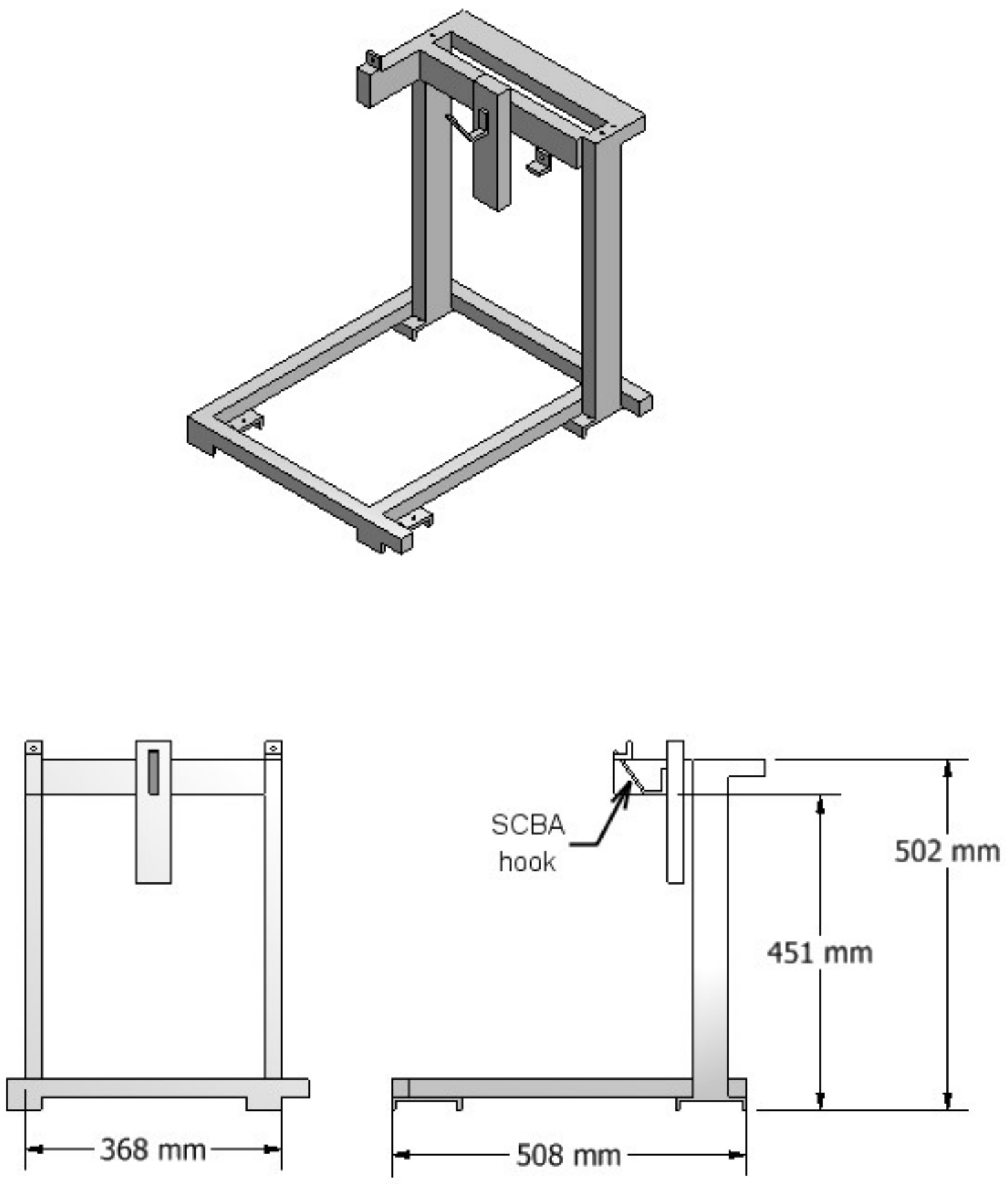

Figure 19. SCBA cart. SCBA pack with air cylinder attached to the hook during experiments. 


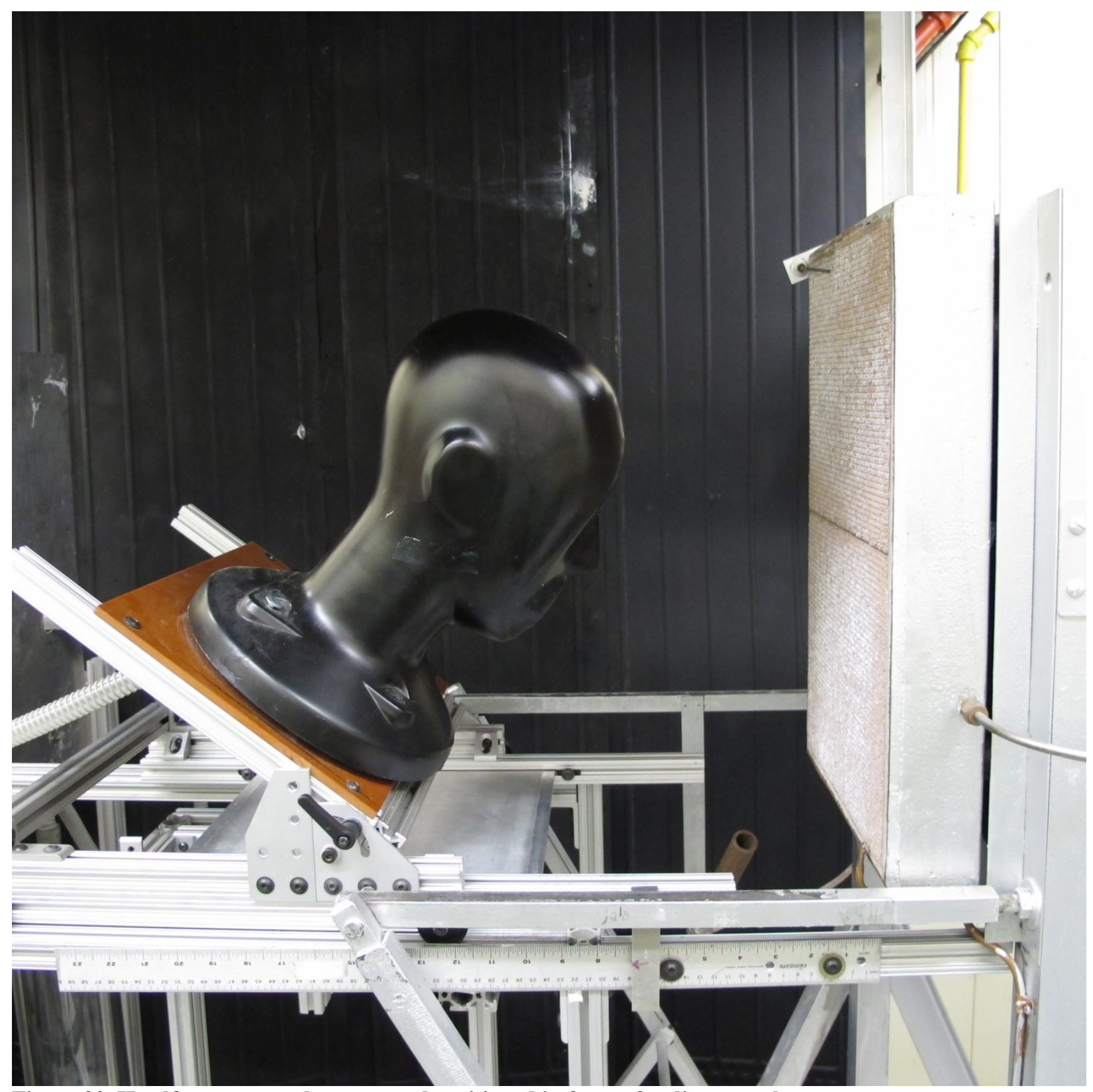

Figure 20. Headform mounted on cart and positioned in front of radiant panel. 


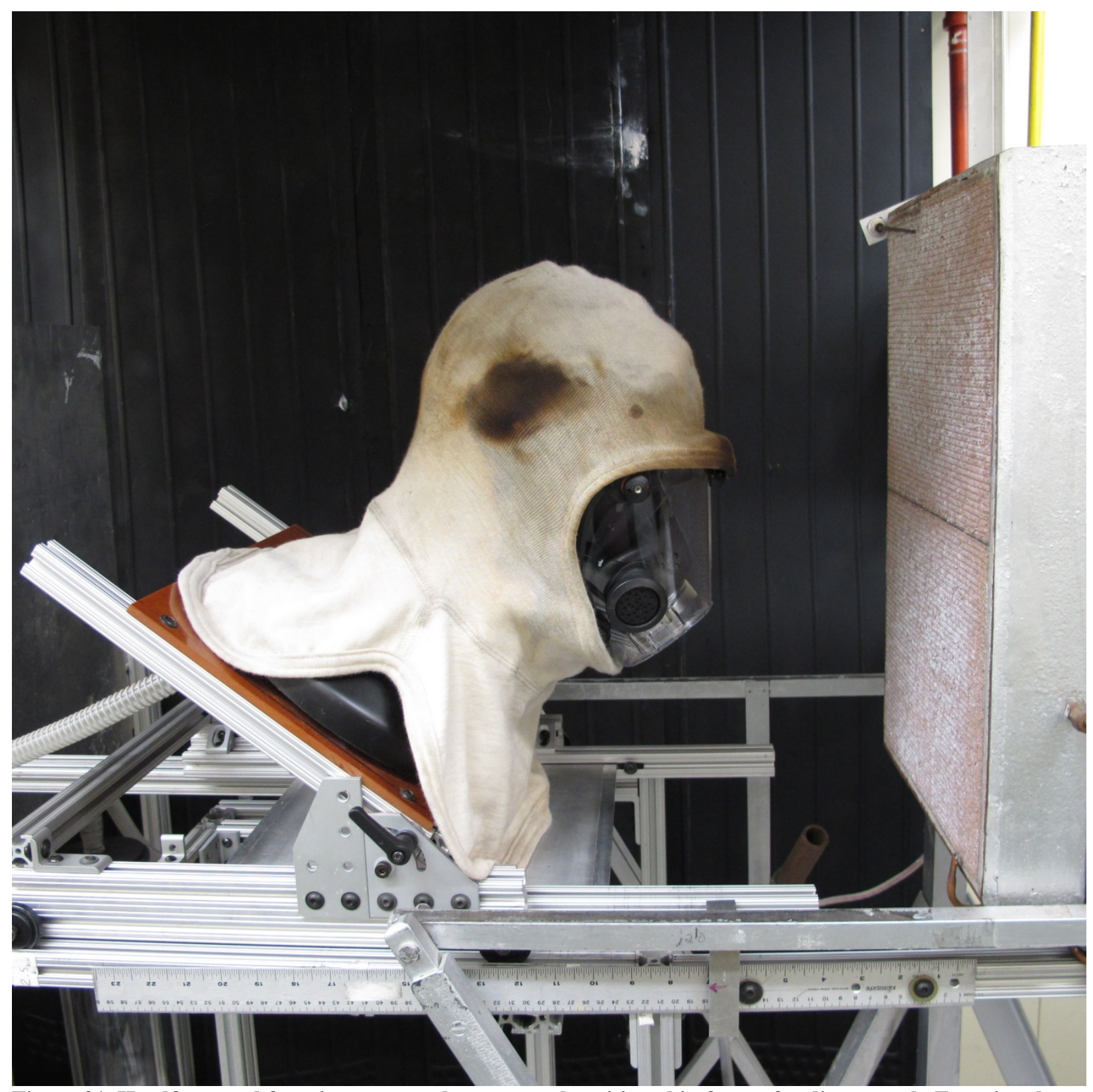

Figure 21. Headform and facepiece mounted on cart and positioned in front of radiant panel. Facepiece lens is parallel with radiant panel, and located approximately $178 \mathrm{~mm}(7.0 \mathrm{in})$ from panel surface. 